\title{
Syntheses and reactivity of calixarenes functionalized at meso positions
}

\author{
Wanda Sliwa and Malgorzata Deska \\ Jan Dlugosz University, Institute of Chemistry, Environmental Protection \\ and Biotechnology, 42-200 Czestochowa, Armii Krajowej 13/15 Street, Poland \\ E-mail: w.sliwa@ajd.czest.pl
}

\begin{abstract}
In this paper the syntheses and reactivity of calixarenes functionalized at their meso positions are reviewed. First the calixarenes substituted at one, two and all meso positions are described; they are followed by presentation of ketocalixarenes.
\end{abstract}

Keywords: Calixarene, conformation, functionalization, meso position, substitution

\section{Table of Contents}

1. Introduction

2. Calixarenes Substituted at One meso Position

2.1. Calix[4]arenes

2.2. Calix[6]arenes

3. Calixarenes Substituted at Two meso Positions

4. Calixarenes Substituted at All meso Positions

5. Ketocalixarenes

6. Conclusion

7. Acknowledgement

8. References

\section{Introduction}

Calixarenes are widely investigated due to their valuable properties, as well as due to their relatively simple syntheses and functionalization. ${ }^{1-4}$ Among various applications of calixarenes one should point out that they may serve as fluorescent sensors ${ }^{5,6}$ and form complexes with metal 
ions, ${ }^{7-9}$ allowing detection of metals; also they find applications in chromatography, ${ }^{2,10}$ and some calixarene derivatives show biological activity. ${ }^{11}$

Calixarenes can be functionalized at their wide ${ }^{12-14}$ and narrow ${ }^{15-17}$ rims, and the present review deals with functionalization of the meso positions of calixarenes. It is noteworthy that functionalization of the meso positions of calixarenes has not been as intensively studied as that of the wide and narrow rims. The paper is a continuation of our work concerning calixarenes. ${ }^{18-22}$

The text consists of four parts, showing calixarenes substituted at one, two, and all meso positions, then ketocalixarenes are briefly described.

\section{Calixarenes Substituted at One meso Position}

Selected examples of calix[4]arenes and calix[6]arenes substituted at one meso position are described, showing their syntheses, reactivity and results of conformational analyses.

\subsection{Calix[4]arenes}

For the synthesis of calix[4]arenes substituted at one meso position, the reaction of calixarene 1 with $n$-butyllithium was used. The formed monolithiated intermediate 2 upon treatment with alkyl or benzyl halides, or carbon dioxide, affords meso monosubstituted calixarenes 3a-d. The substituted tetramethoxycalixarenes 3a-c react with boron tribromide to give the corresponding tetrahydroxycalixarenes $\mathbf{4 a - c} .^{23}$
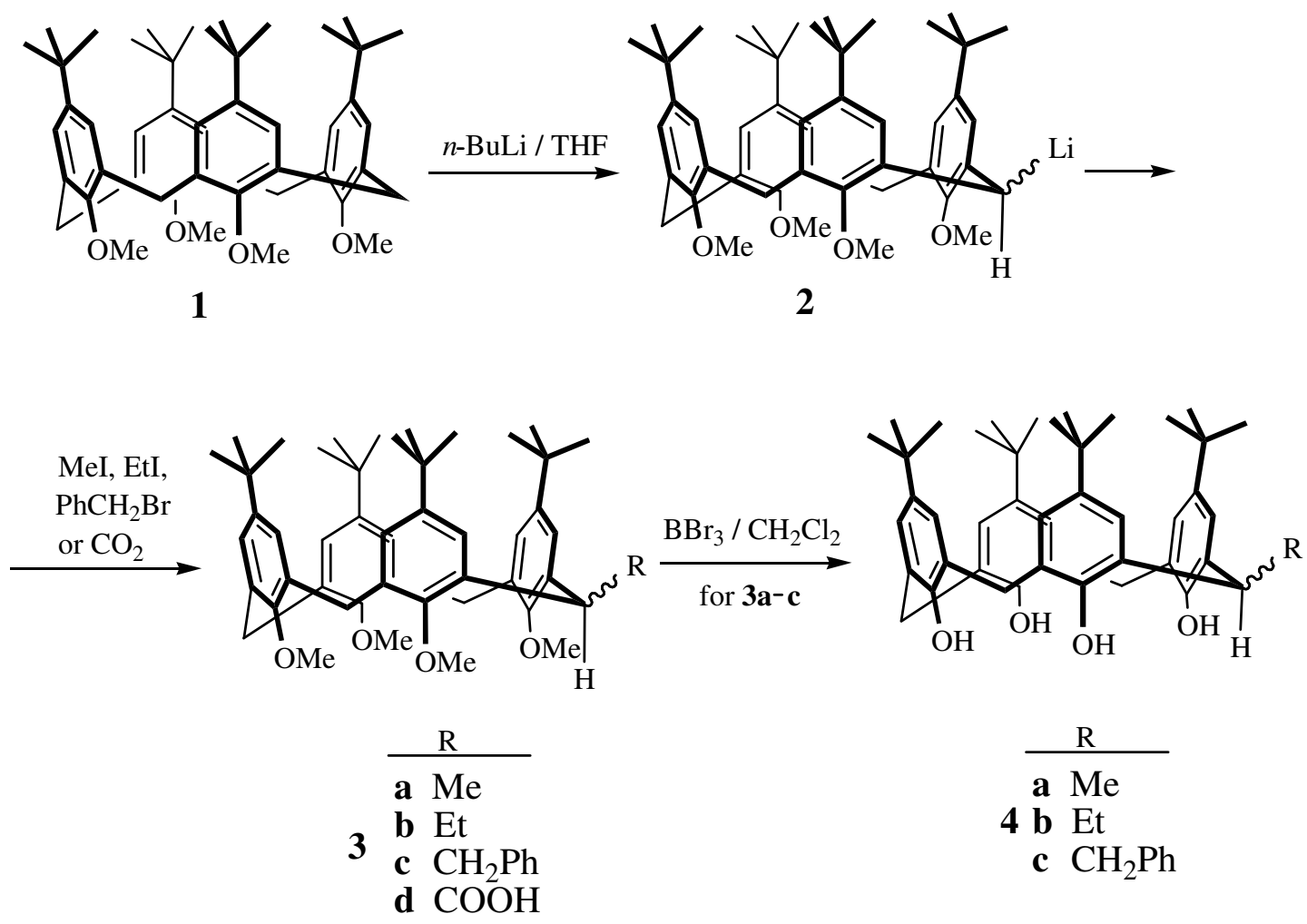
The same procedure leading to $\mathbf{2}$ served for subsequent attachment of chloro or iodo, pyridinium and amino moieties at the end of the alkyl tether of 3-6 carbon atoms at a single meso position of calixarene $1 .^{24}$ The reaction of 2 with 1-bromo- $\omega$-chloroalkanes containing 3-6 carbon atoms, gave $\mathbf{5}$.

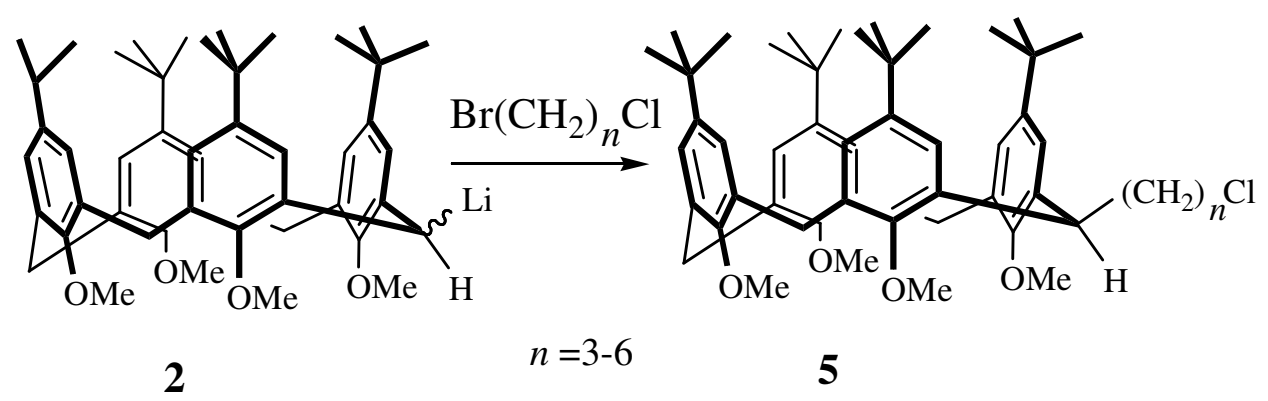

It was found that $5(n=3-5)$ treated with $\mathrm{NaI}$ afforded iodo derivatives $6(n=3-5)$, while the reaction with pyridine yielded pyridinium salts $7(n=3-5)$.

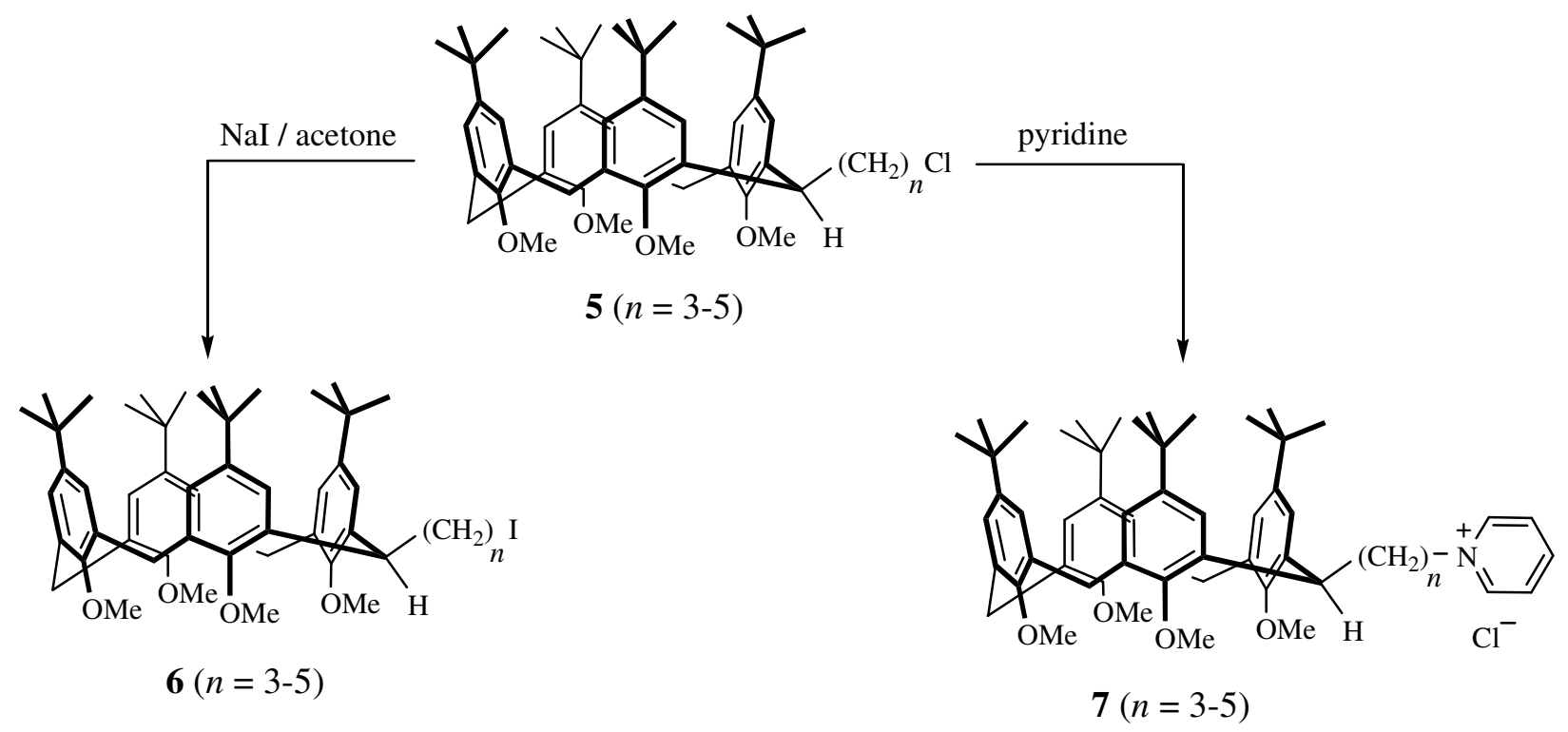

For attachment of amines to the meso position of calixarenes, as an example, the reaction of 5 ( $n=3$ or 5 ) with cyclohexylamine leading to derivatives 8 is shown: 


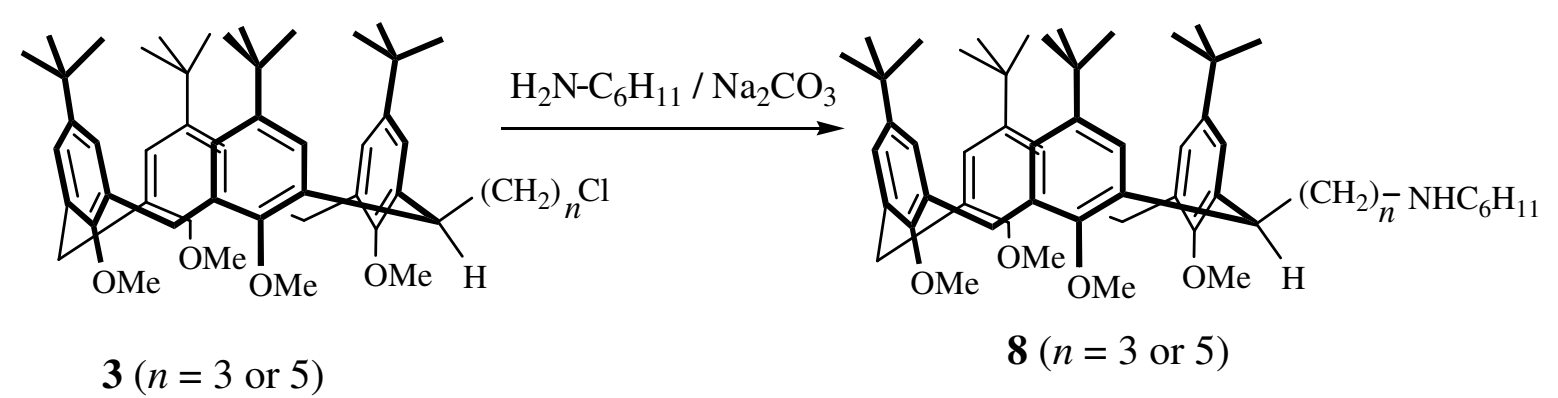

The attachment of aniline or its derivatives required their conversion into their potassium salts. Thus, calixarene $\mathbf{5}(n=4,5)$ was treated with previously prepared potassium salts of aniline or its derivatives to give compounds $9(n=4,5)$.

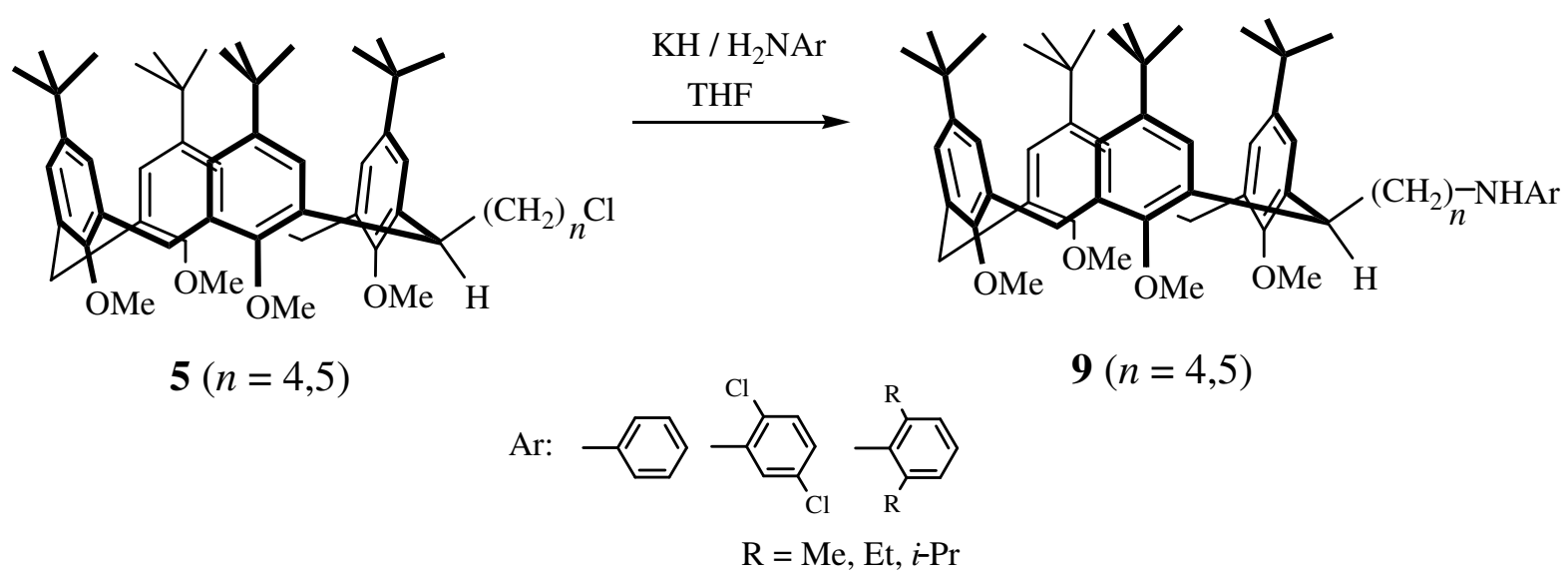

It should be noted that the above syntheses of amine-functionalized calixarenes enable their metallation or binding to solid supports. ${ }^{24}$

In the study of calixarenes, substituted at a single meso position ${ }^{25,26}$ compound $\mathbf{3 d}$ was reduced to give the alcohol 10, and was esterified to give esters $11 \mathbf{a}-\mathbf{c}^{27}$ 


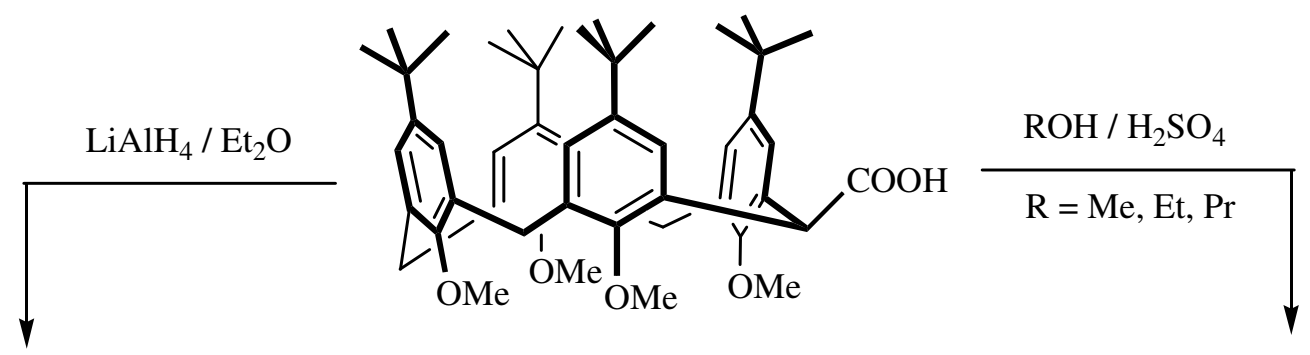

3d

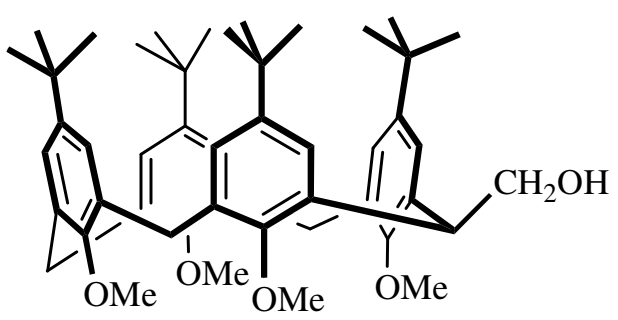

10

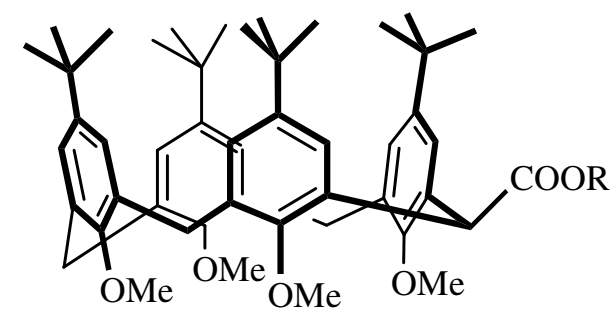

$\mathrm{OMe}{ }_{\mathrm{OMe}}^{\mathrm{OMe}}$

Alcohol 10 was methylated with MeI affording the ether 12 and was dansylated using dansyl chloride to give the fluorescent sulfonate ester $\mathbf{1 3}$ which is sensitive to $\mathrm{Cu}$ (II) ions.

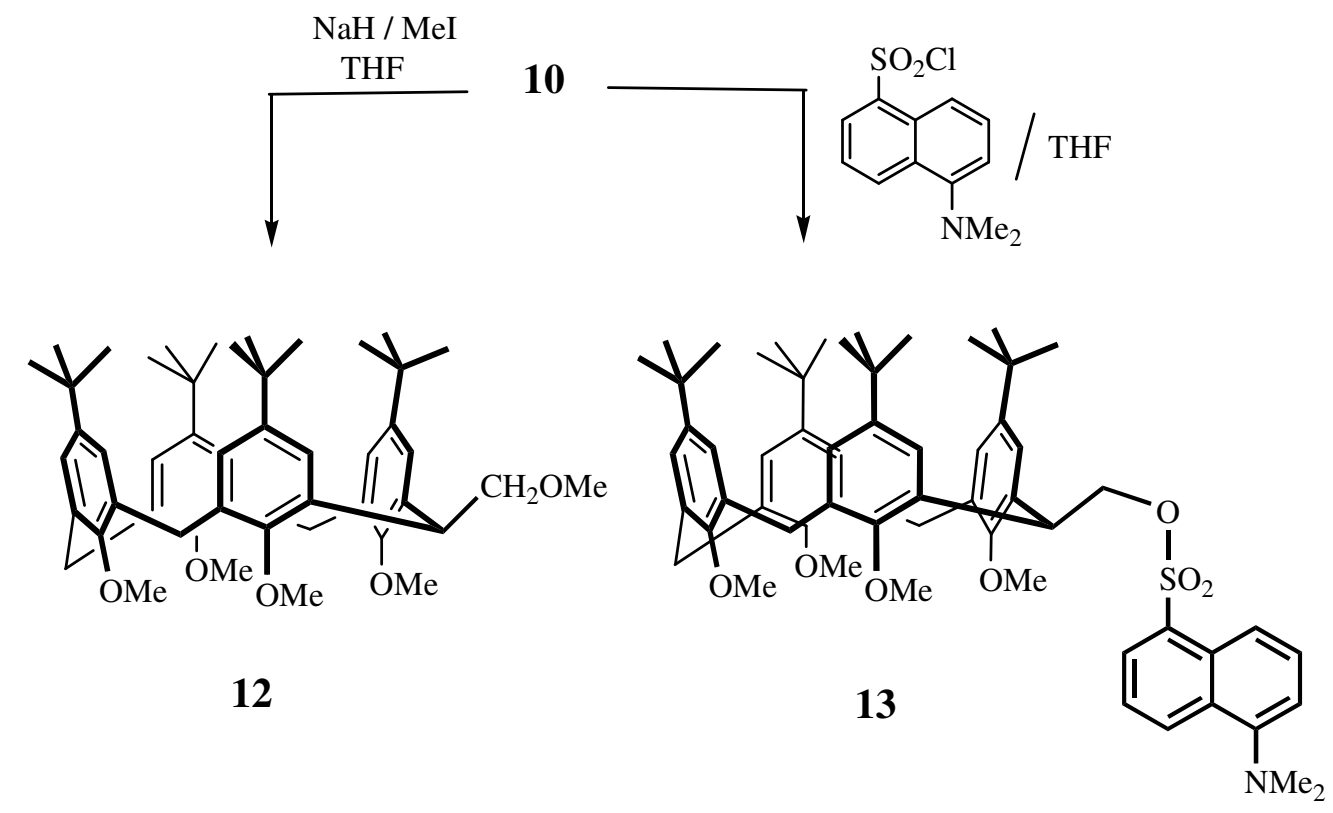

However the attempted conversion of $\mathbf{3 d}$ to an amide unexpectedly afforded lactone $\mathbf{1 4 .}$ 


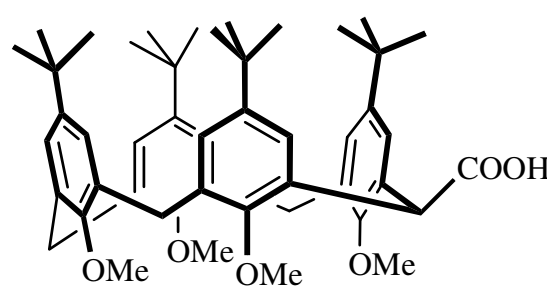

3d

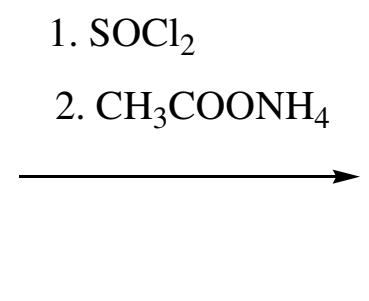

2. $\mathrm{CH}_{3} \mathrm{COONH}_{4}$

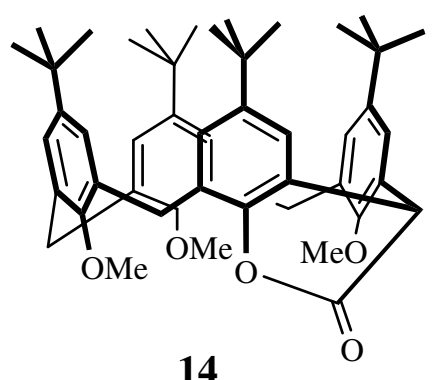

14

The conformational analysis of calixarene $\mathbf{3 d}$ has been performed in solution and in crystalline state. It was found that calixarene $\mathbf{3 d}$ in $\mathrm{CDCl}_{3}$ undergoes a fast interconversion of phenyl units. The steric crowding of $t$-butyl groups on the wide rim exists, therefore the less symmetrical paco conformers prevail, while the more symmetrical cone and 1,2-alt are not favored. The existence of a special monomeric paco-1 conformation of $\mathbf{3 d}$ with an intramolecular hydrogen bond in apolar solvents was confirmed by DOSY NMR measurements and MM calculations; it was found that cone, paco-2 and 1,2-alt conformers of $\mathbf{3 d}$ form aggregates. ${ }^{28}$

The crystal structures of unsolvated $\mathbf{3 d}$ as well as of two mixed solvent complexes 15a, i.e. $\mathbf{3 d} \cdot \mathrm{EtOH} \bullet \mathrm{H}_{2} \mathrm{O}(1: 1: 1)$ and $\mathbf{1 5 b}$, i.e. $\mathbf{3 d} \cdot \mathrm{EtOH} \cdot \mathrm{THF}(1: 1: 1)$ are reported. It is of interest that in paco 3d the carbon atom of the $\mathrm{CH}_{2}$ group, bearing the carboxyl group becomes a centre of chirality due to the asymmetric geometry of the calixarene; this is a rare conformational chirality isomerism. The above investigation of $\mathbf{3 d}$ is promising for use of similarly substituted calixarenes in design of nanostructures ${ }^{29}$ and of immobilized devices. ${ }^{30}$

\subsection{Calix[6]arenes}

In order to obtain calix[6]arenes substituted at one meso position, the photochemical reaction of calixarene 16 with NBS was performed. The resulting bromination of a single meso position, followed by hydrolysis afforded the desired calixarene $\mathbf{1 7}$ which is hydroxylated at a single meso position.

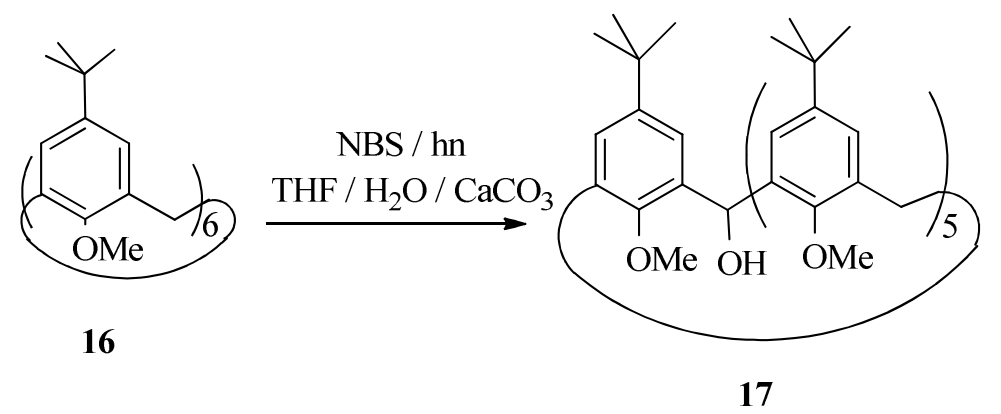

Calixarene $\mathbf{1 7}$ is a starting material for synthesis of a wide range of calixarenes functionalized at a single meso position. Thus the treatment of $\mathbf{1 7}$ with thionyl chloride yields 
calixarene 18 which upon reaction with 2-propanol or with TFE gives calixarenes 19a,b, and upon reaction with $m$-xylene or with $p$-t-butylphenol yields $\mathbf{2 0 a}, \mathbf{b}$, respectively. ${ }^{31}$

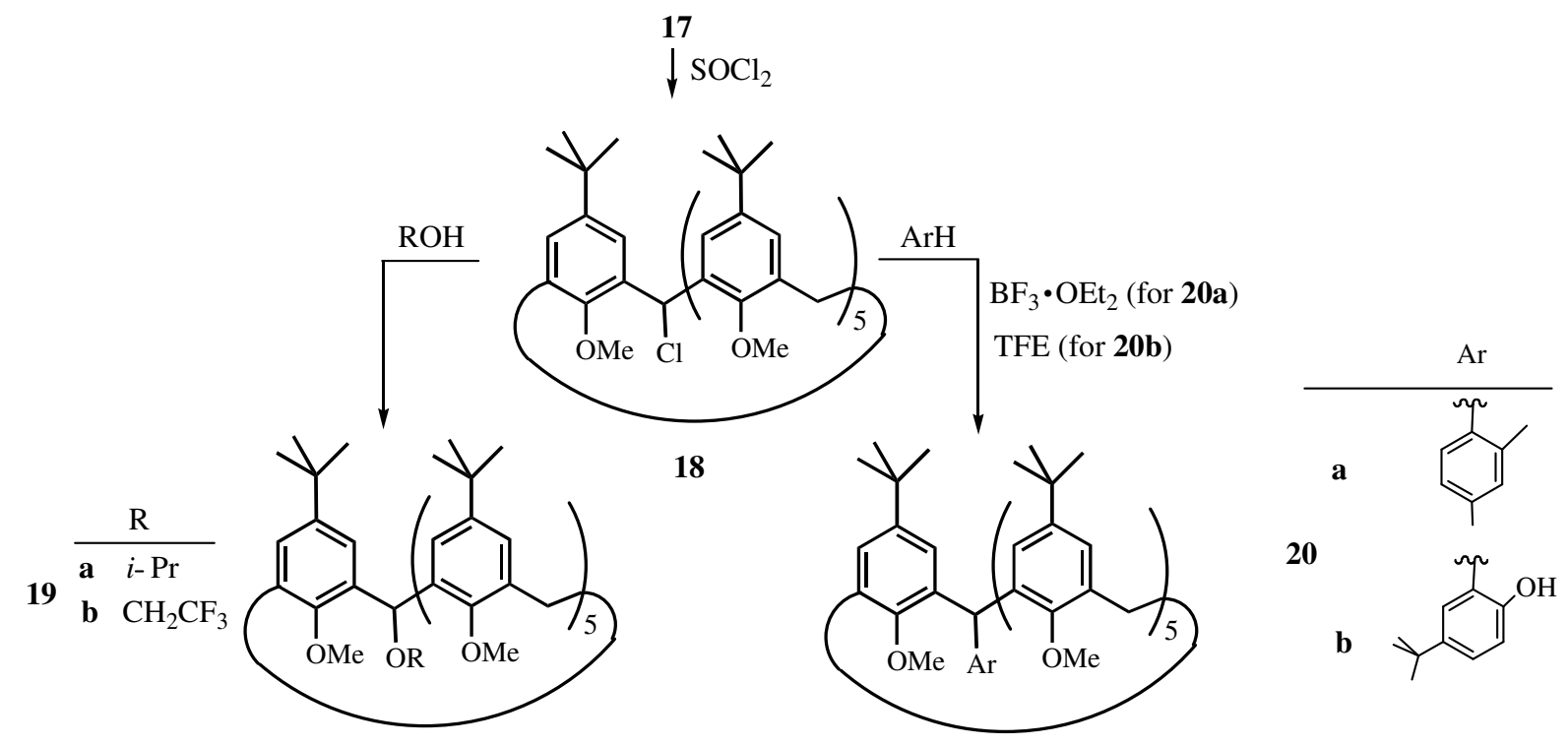

It was found also that 17 reacts with $\mathrm{Et}_{2} \mathrm{NSF}_{3}$ (deoxofluorinating agent DAST) via replacement of the hydroxyl group by fluorine, affording 21; one should mention that $\mathbf{2 1}$ is the first example of a calixarene functionalized by fluorine atom at the single meso position.
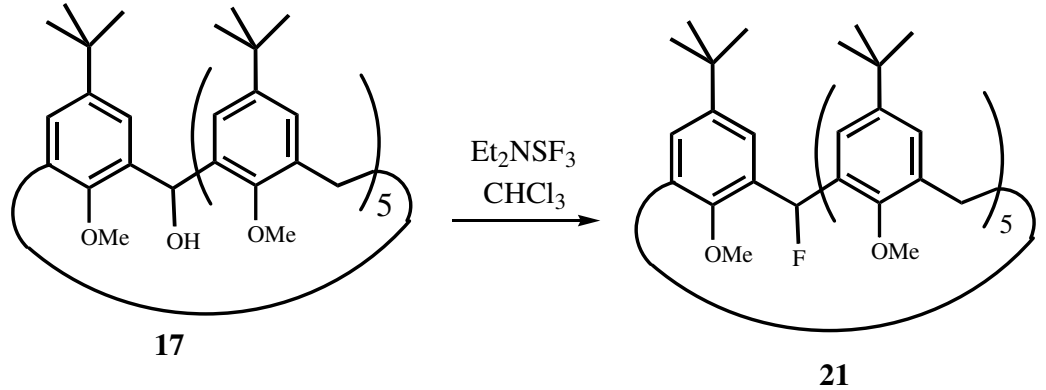

The above investigation has shown that easily available hydroxy- and chloro-functionalized calixarenes $\mathbf{1 7}$ and $\mathbf{1 8}$ are valuable starting materials for a variety of calixarenes substituted at one meso position. ${ }^{31}$

\section{Calixarenes Substituted at Two meso Positions}

In the first part of this section, calixarenes meso disubstituted by various nucleophiles are shown; then the functionalization of meso positions of calixarenes by ortho-Fries rearrangement is described.

It was established that calixarene 22 upon mild oxidation with phenyl trimethylammonium tribromide 23 affords bis(spirodienone)calix[4]arene 24, which by a bromination/debromination sequence, via compound 25 yields dibromoderivative 26. Reaction of $\mathbf{2 6}$ with nucleophiles leads 
to trans-disubstituted bis(spirodienone)calixarenes 27 which upon reduction with $\mathrm{LiAlH}_{4}$ give trans-disubstituted calixarenes $\mathbf{2 8}{ }^{32}$

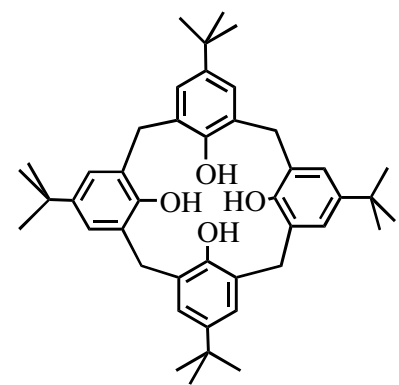

22

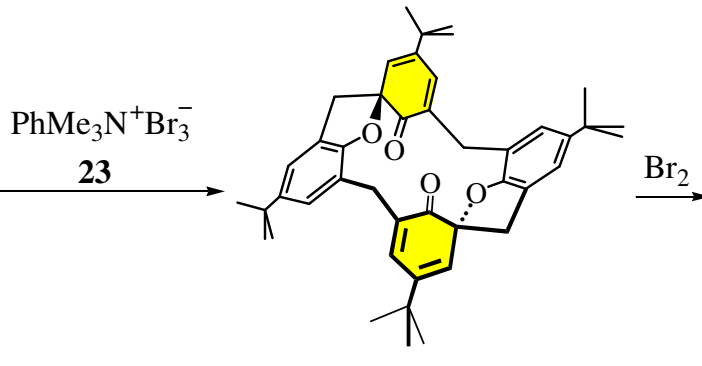

24

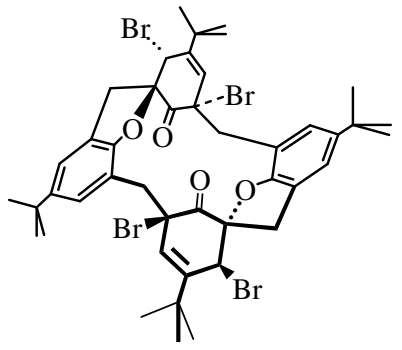

25

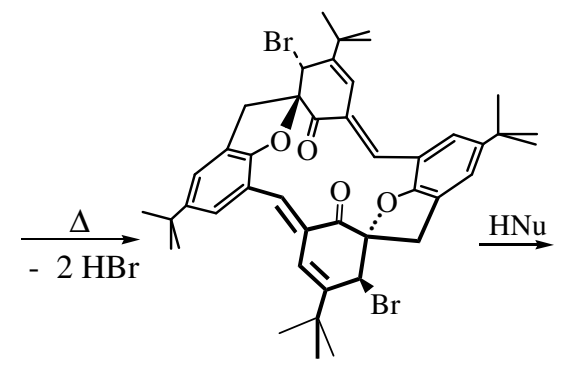

26

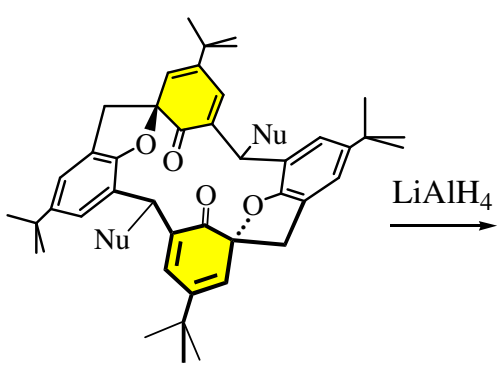

27

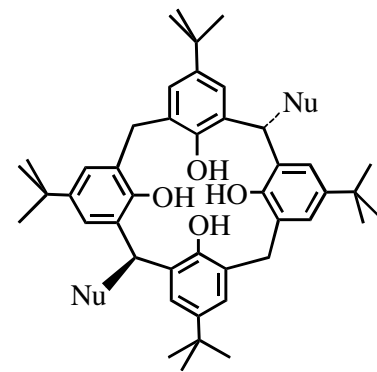

28

$\mathrm{Nu}=\mathrm{OEt}, \mathrm{SMe}, \mathrm{NHPh}, \mathrm{CH}(\mathrm{COOEt})_{2}$

Calixarene 26 reacts with oxygen, sulfur, nitrogen and carbon nucleophiles, ${ }^{33}$ these processes are presented below.

\section{- Oxygen nucleophiles}

For oxygen nucleophiles, $\mathrm{MeO}^{-}$and $\mathrm{EtO}^{-}$were used affording 29a,b.

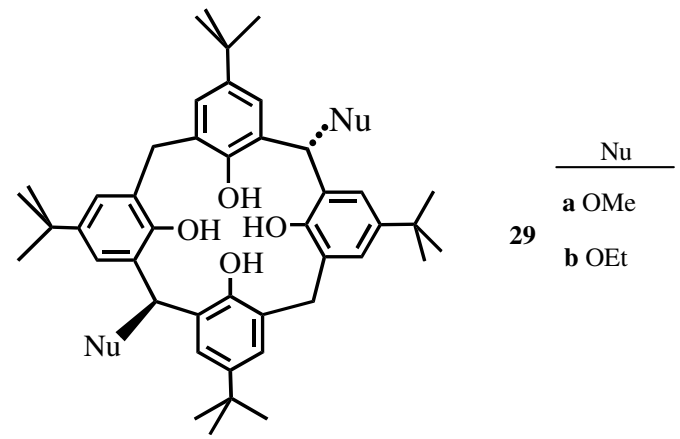

\section{- Sulfur nucleophile}

The reaction of $\mathbf{2 6}$ with NaSMe was performed using THF as a solvent; it was found that the results depend upon the dryness of THF. The reaction made in "wet" THF yielded the expected disubstituted bis(spirodienone)calixarene 30, while in dry THF the meso trans-disubstituted calixarene 31 was formed. The $\mathrm{LiAlH}_{4}$ reduction of $\mathbf{3 0}$ may also afford calixarene $\mathbf{3 1}$. 


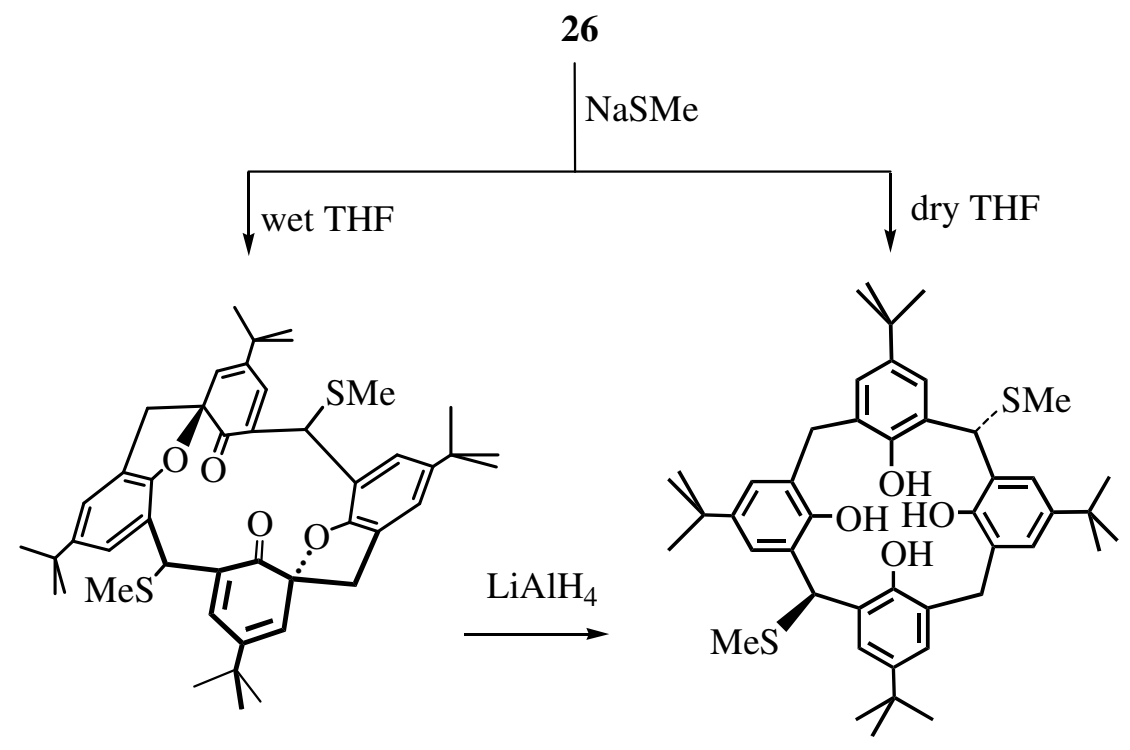

30

31

The obtained trans $\mathbf{3 1}$ undergoes a thermal isomerization to give more stable cis $\mathbf{3 1}$.<smiles>C[C@H](c1cc(C(C)(C)C)cc(O)c1O)c1cc(C(C)(C)C)cc(Cc2cc(C(C)(C)C)cc([C@@H](C)c3cc(C(C)(C)C)cc([C@@H](C)c4cc(C(C)(C)C)cc(Cc5cc(C(C)(C)C)cc(C(C)(C)C)c5O)c4O)c3O)c2O)c1O</smiles>

trans 31

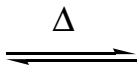<smiles>C[C@@H](c1cc(C(C)(C)C)cc(C(C)(C)C)c1)c1cc(C(C)(C)C)cc(Cc2cc(C(C)(C)C)cc([C@H](C)c3cc(C(C)(C)C)cc(Cc4cc(C(C)(C)C)cc([C@H](C)c5cc(C(C)(C)C)cc(C(C)(C)C)c5O)c4O)c3O)c2O)c1O</smiles>

cis 31

\section{- Nitrogen nucleophiles}

a) The reaction of $\mathbf{2 6}$ with sodium azide affords $\mathbf{3 2}$. One may confirm this result by using Huisgen click reaction with an alkyne, however in order to avoid the concomitant Diels-Alder reaction of alkyne with the two diene systems of $\mathbf{3 2}$, the $\mathrm{NaBH}_{4}$ reduction of $\mathbf{3 2}$, leading to $\mathbf{3 3}$, was made. Treatment of $\mathbf{3 3}$ with dimethyl acetylenedicarboxylate yielded the desired $\mathbf{3 4}$ bearing two 1,2,3-triazole units. 


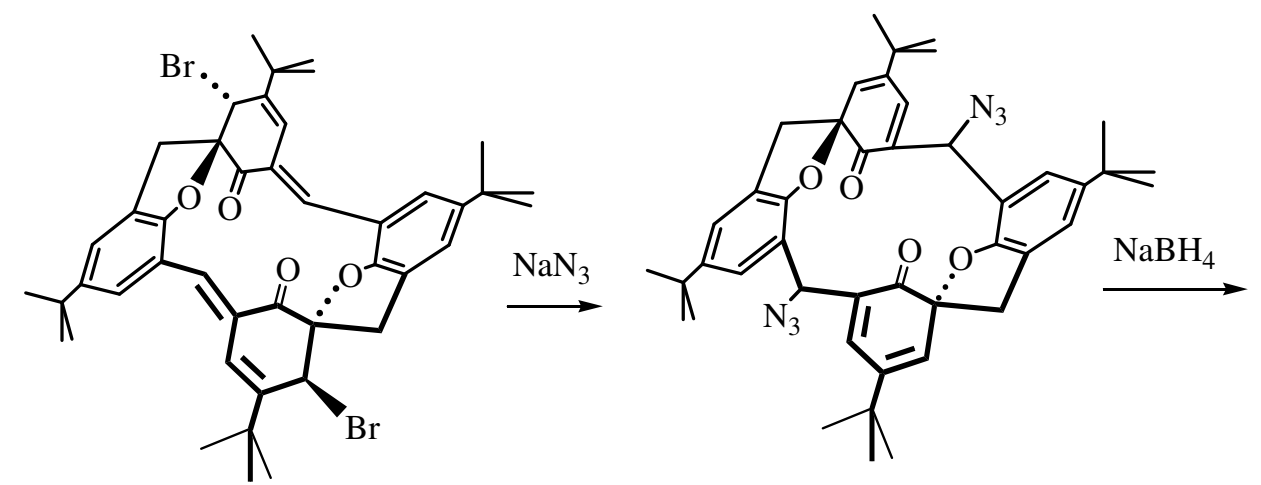

26

32

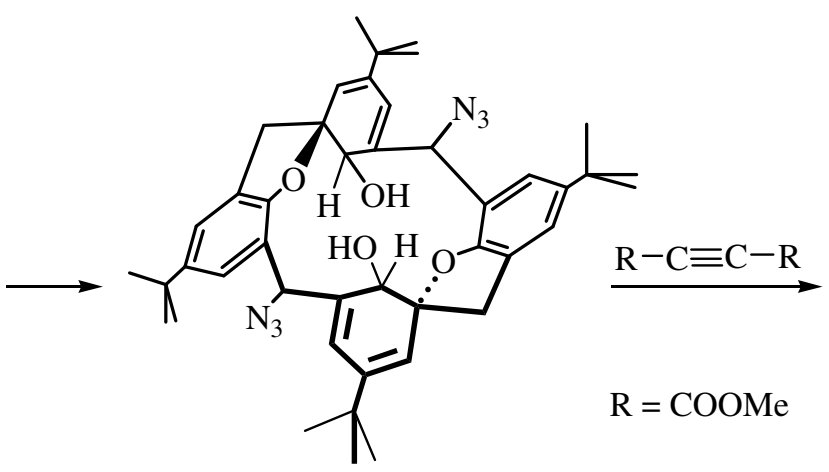

33

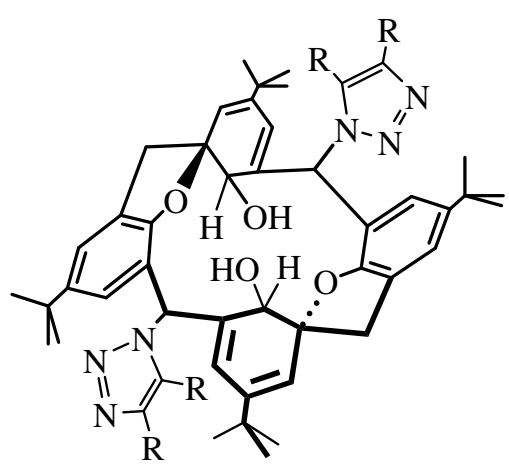

34

b) The reaction of $\mathbf{2 6}$ with aniline afforded $\mathbf{3 5}$ which was reduced with $\mathrm{LiAlH}_{4}$ to give calixarene 36 .

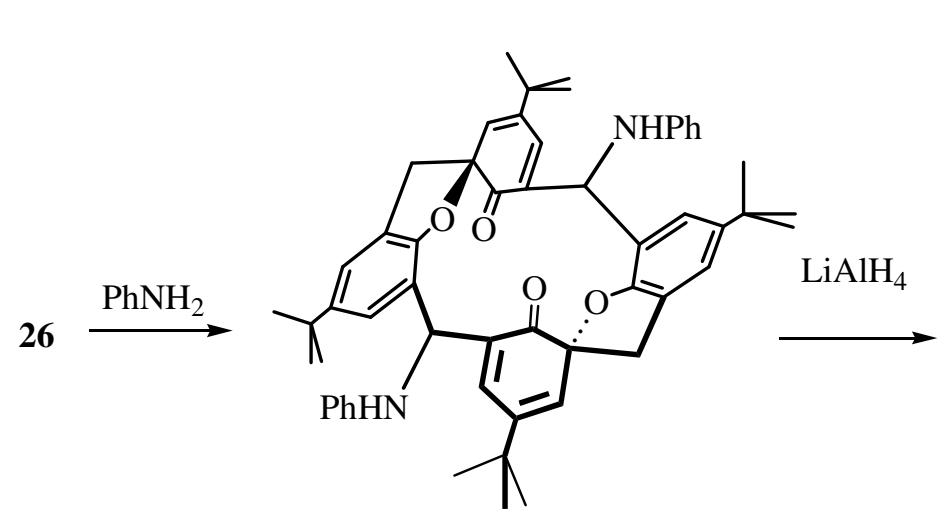

35

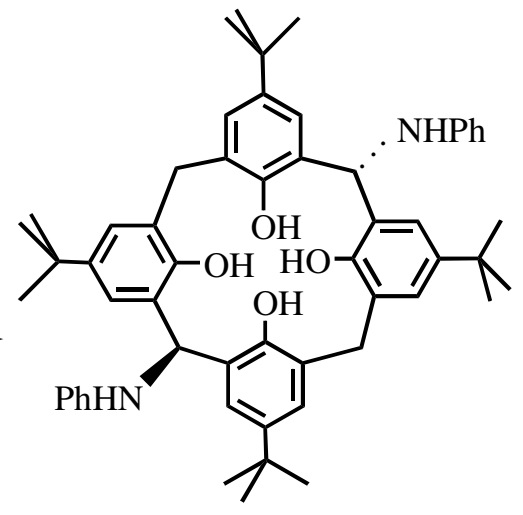

36

\section{- Carbon nucleophiles}

The reaction of $\mathbf{2 6}$ with sodium enolates of acetylacetone or diethyl malonate yielded $\mathbf{3 7}$ and $\mathbf{3 8}$, respectively. The subsequent $\mathrm{LiAlH}_{4}$ reduction of $\mathbf{3 8}$ gave calixarene $\mathbf{3 9}$. 

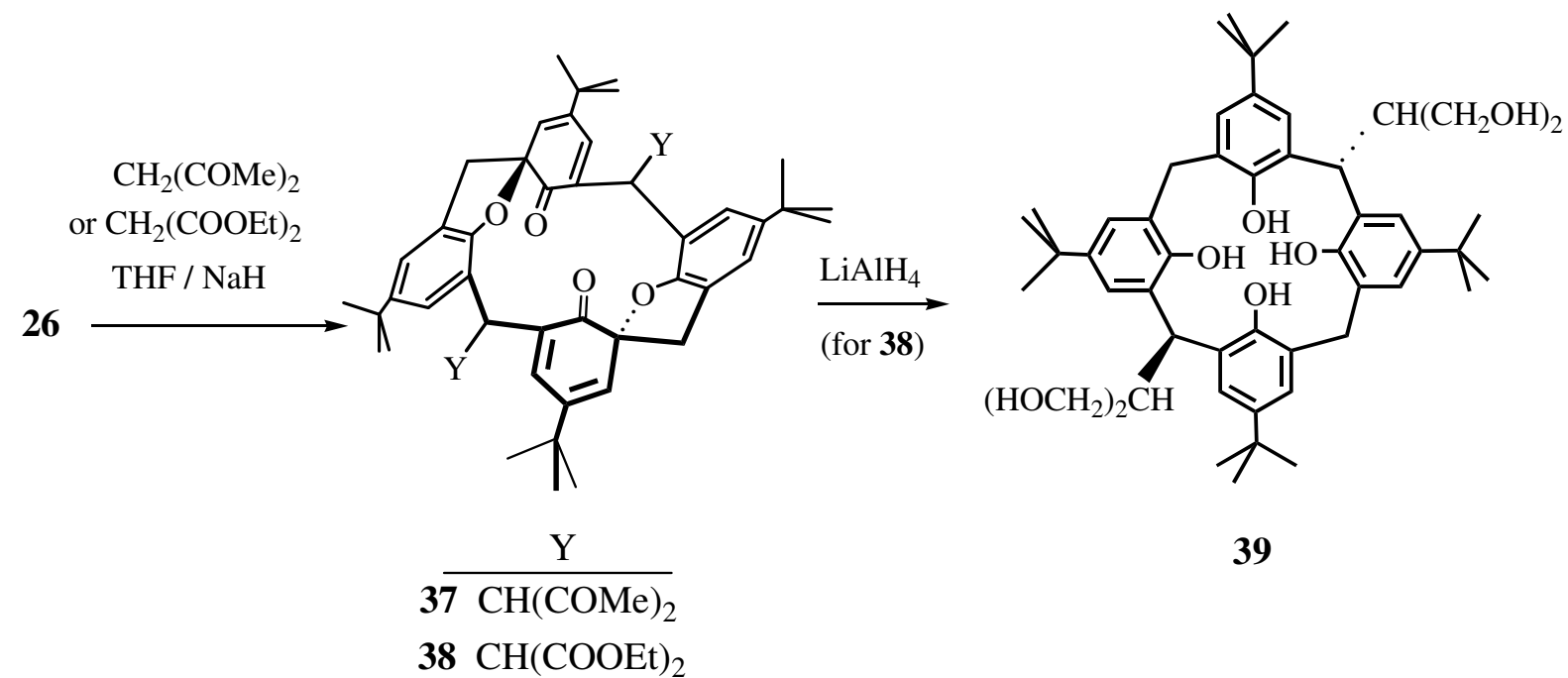

It was observed that $\mathbf{2 6}$ reacts with tetrabutylammonium fluoride (TBAF) to give difluorinated bis(spirodienone)calixarene 40 which upon reduction afforded trans-difluorinated compound 41. In order to substitute meso positions with alkyl groups, the reactions of 26 with $\mathrm{RMgX} / \mathrm{CuCN}$ (for $\mathrm{R}=\mathrm{Me}$ or $\mathrm{Et}, \mathrm{X}=\mathrm{Br}$; for $\mathrm{R}=i$ - $\mathrm{Pr}, \mathrm{X}=\mathrm{Cl}$ ) were carried out to give transdisubstituted calixarenes $42 a-c{ }^{32}$ 


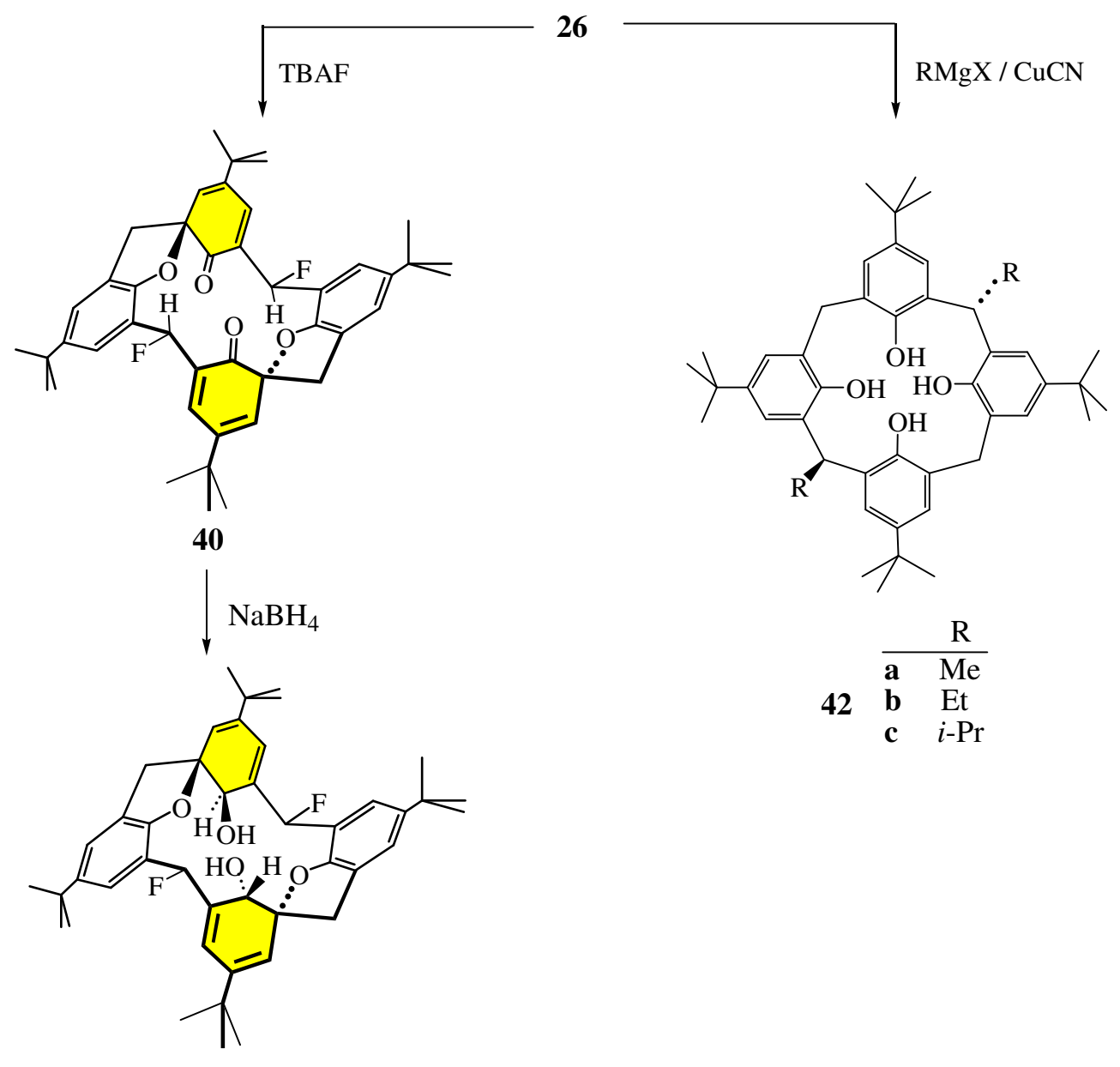

41

Compound 26 is also the starting material for synthesis of calixarenes meso transdisubstituted by phenyl and mesityl groups, 43 and 44, respectively; the reaction of 26 with $\mathrm{PhMgBr} / \mathrm{CuCN}$ affords $\mathbf{4 3}$, while the reaction of $\mathbf{2 6}$ with $\mathrm{MesMgBr} / \mathrm{CuCN}$ leads to formation of bis(spirodienone)calixarene $\mathbf{4 5}$ which upon reduction with $\mathrm{LiAlH}_{4}$ yields 44.

The cone conformation of parent calixarene $\mathbf{2 2}$ is stabilized by the existence of the circular array of hydrogen bonds between hydroxyl groups. It was observed that meso diphenyl calixarene $\mathbf{4 3}$ also adopts the cone conformation, whereas meso dimesityl calixarene $\mathbf{4 4}$ has the 1,2-alt conformation due to the presence of bulky mesityl substituents. ${ }^{34}$ 


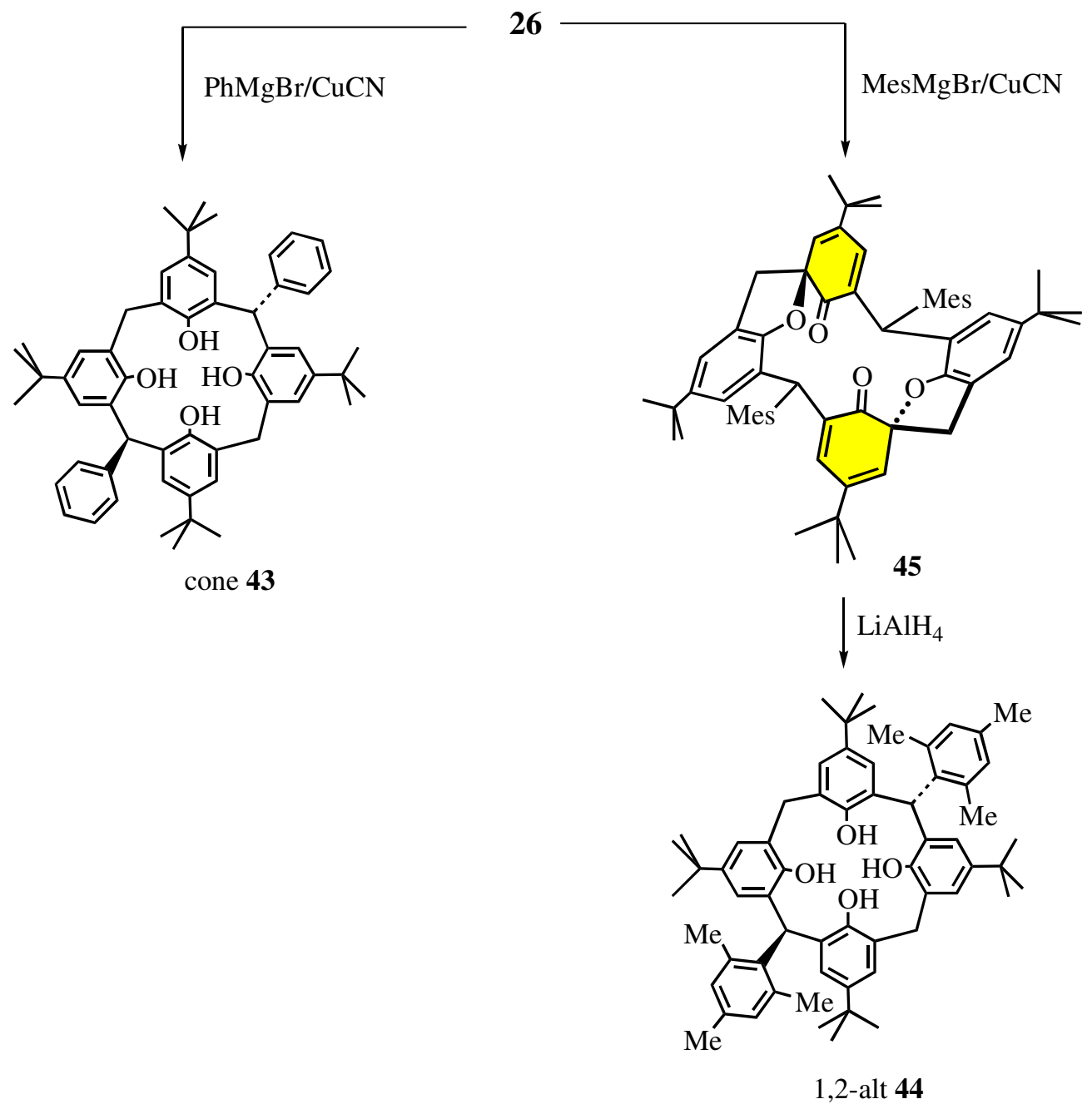

In order to obtain compounds related to spirodienonecalix[6]arenes, the mild oxidation of the macrocycle 46, joining structural features of calixarenes and spherands, was performed with $\mathbf{2 3}$ in a similar way as for calix[4]arene $\mathbf{2 2}$. It was found that the reaction result depends on the amount of used 23: the oxidation with one or two 23 equivalents leads to products 47 and 48 containing one or two spirodienone units, respectively, whereas the use of three $\mathbf{2 3}$ equivalents affords two isomeric compounds $\mathbf{4 9}$ and $\mathbf{5 0}$ containing three spirodienone units. It was observed that the oxidation of $\mathbf{4 8}$ with iodine in aqueous $\mathrm{KOH}$ solution also yields $\mathbf{4 9}$ and $\mathbf{5 0} .^{35}$ 


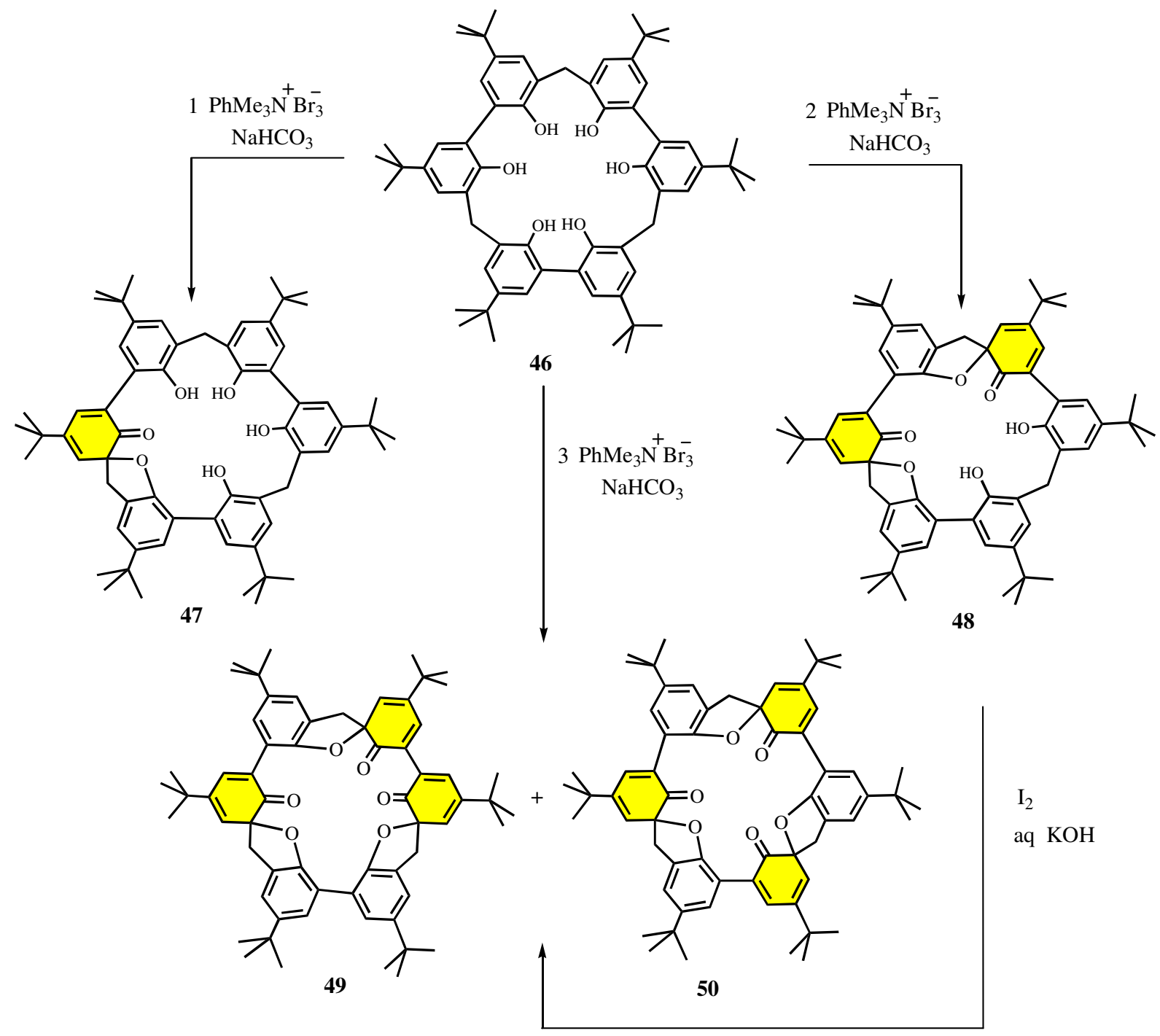

Compounds 49 and 50 isomerize upon heating in the solid state and in benzene solution; in equlibrium mixture 49 is the major component. ${ }^{35}$

Calixarenes meso trans disubstituted by alkyl, allyl, p-bromobenzyl and carboxyl groups have been obtained via a simple two-step procedure. ${ }^{36}$ The first step involves lithiation of one meso position of 51 followed by reaction with bromoderivatives $\mathrm{RBr}(\mathrm{R}=\mathrm{Me}$, Et, allyl) or with $\mathrm{CO}_{2}$. The obtained monosubstituted products 52-55 adopt a paco conformation in $\mathrm{CDCl}_{3}$ solution, however addition of small amounts of $\mathrm{NaI}$ and acetonitrile- $d_{3}$ leads to their cone conformation, this behavior being due to complexation of the sodium ion with the methoxy group. 


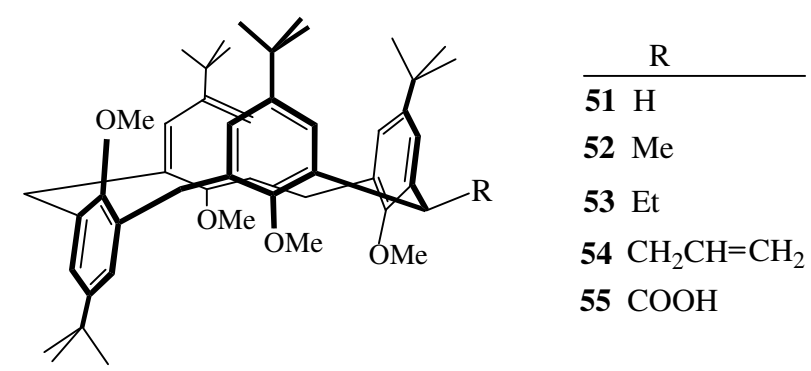

One should mention that the calixarene $\mathbf{5 5}$ bearing carboxyl group may be converted into its methyl ester 56 by esterification with methanol; this compound may be also obtained from calixarene $\mathbf{5 1}$ by lithiation and subsequent treatment with methyl chloroformate.

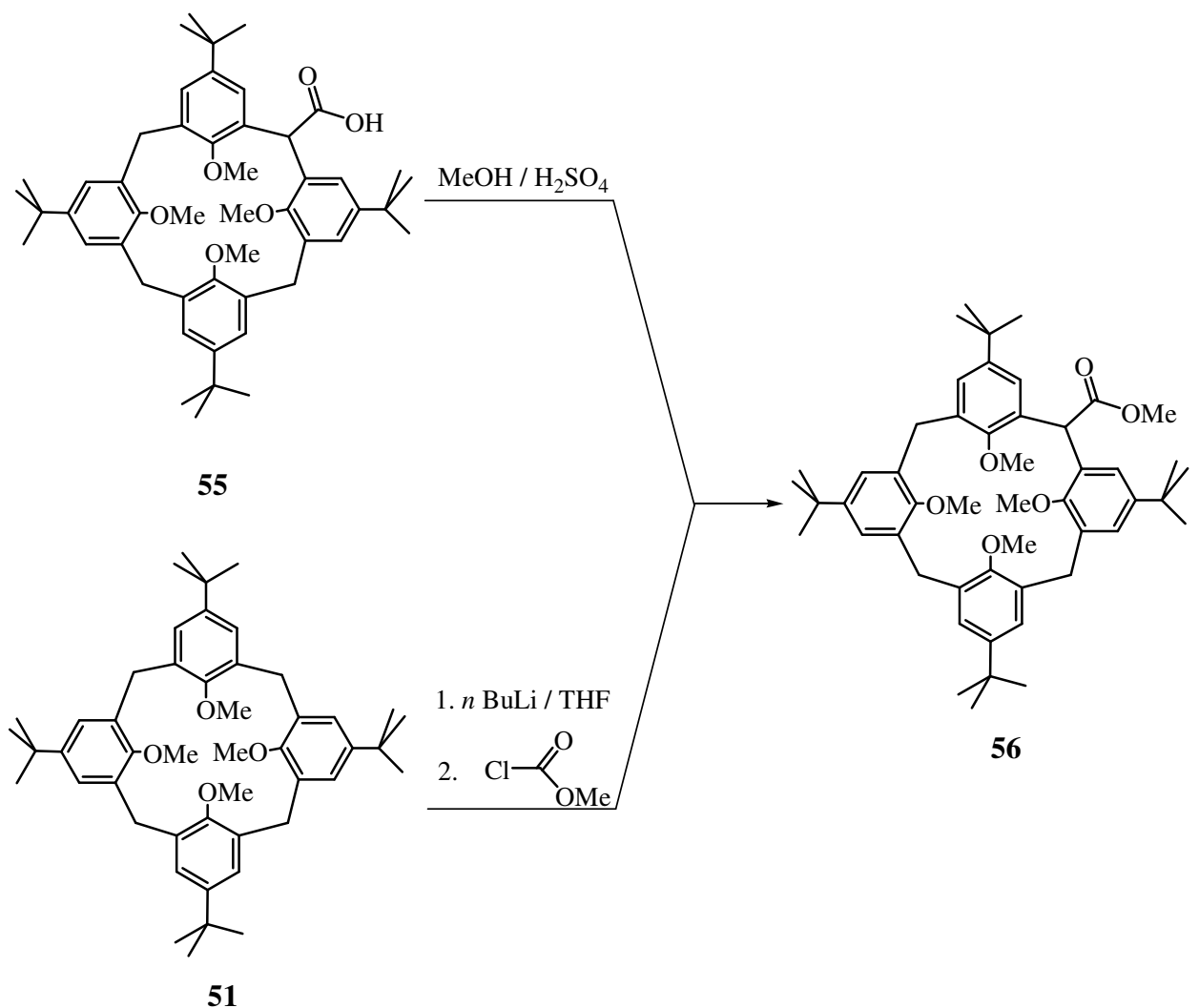

The second step leads to conversion of monosubstituted calixarenes 52-55 into calixarenes 57-64 containing two equal or different substituents at meso trans positions; this second step involves lithiation followed by substitution with use of RX. To avoid side processes with the first substituent, these reactions were conducted at $-78^{\circ} \mathrm{C}$. It was found that 52 reacts with $\mathrm{MeBr}$ or $\mathrm{CO}_{2}$ to give 57 or 58, respectively; similarly 54 reacts with allyl bromide or $\mathrm{CO}_{2}$ affording 63 or 64. 


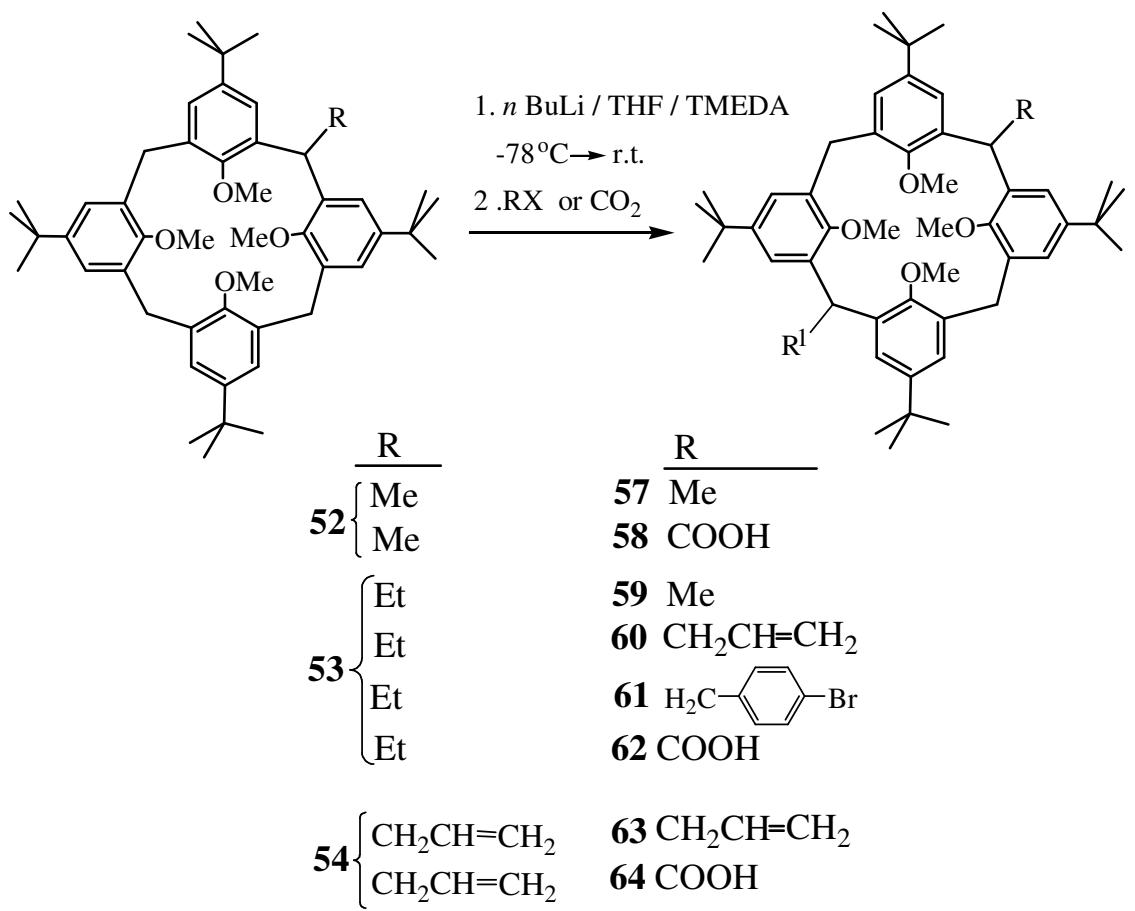

The obtained calixarenes 57-64, adopting rare 1,2-alt conformation in solution and in the solid state are promising for design of supramolecular receptors. ${ }^{36}$

The functionalization of meso positions of calixarenes may be achieved using ortho-Fries rearrangement of calixarene bis- $O$-carbamates. In these experiments cone, paco and 1,3-alt calixarenes 65a,b-67a,b were reacted with LDA in THF to give products 68-77. The rearrangement was made from starting materials substituted by $O-\mathrm{C}(\mathrm{O}) \mathrm{NEt}_{2}$ groups; for synthesis of $68 \mathrm{~b}, 69 \mathrm{~b}, \mathbf{7 2 b}$ and $73 \mathrm{~b}$ the starting materials substituted by $O-\mathrm{C}(\mathrm{O}) \mathrm{NMe}_{2}$ groups were used. ${ }^{37}$

\section{starting calixarene $O$-carbamates}

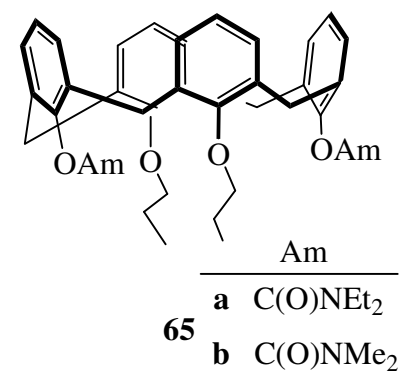

cone

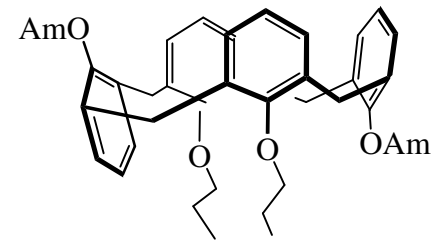

66 $\begin{array}{ll}\text { a } & \mathrm{Am}=\mathrm{C}(\mathrm{O}) \mathrm{NEt}_{2} \\ \text { b } & \mathrm{Am}=\mathrm{C}(\mathrm{O}) \mathrm{NMe}_{2}\end{array}$

paco

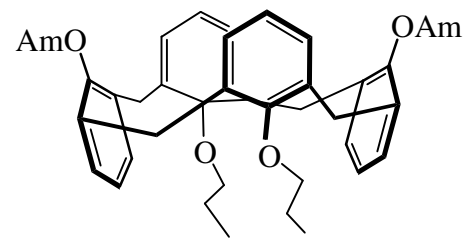

a $\mathrm{Am}=\mathrm{C}(\mathrm{O}) \mathrm{NEt}_{2}$

${ }^{67}$ b $\mathrm{Am}=\mathrm{C}(\mathrm{O}) \mathrm{NMe}_{2}$

$1,3-$ alt 


\section{$\underline{\text { mono-rearranged products }}$}

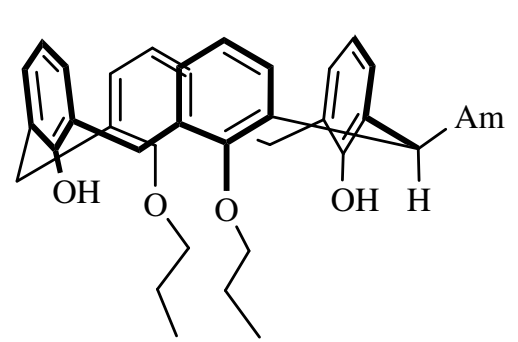

eq $68 \mathbf{a}, \mathbf{b}$

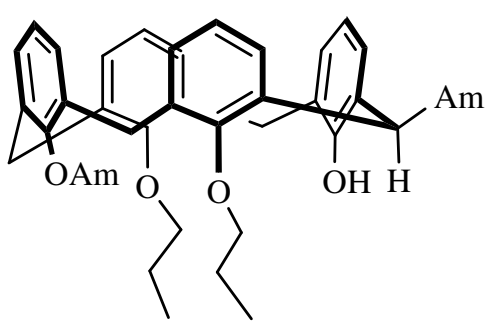

eq 69a,b

\section{bis-rearranged products}

-proximal:

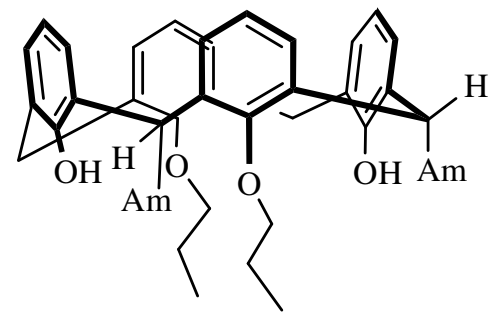

ax, ax 70a

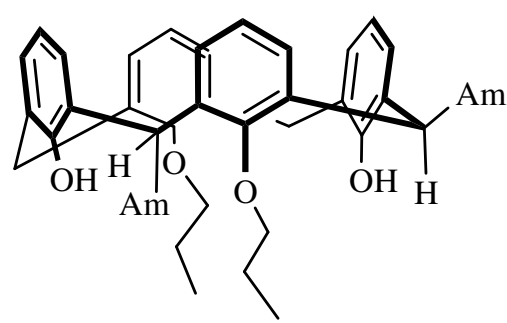

ax,eq 71a

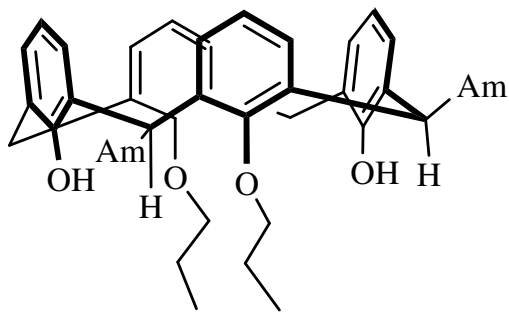

eq,eq 72a,b

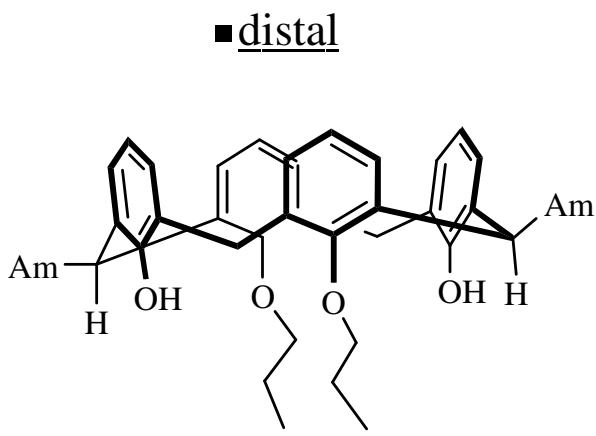

eq,eq 73a,b

The reactions afforded rearranged cone calixarenes 68-73, namely mono-rearranged: 68a,b (equatorial) and 69a,b (equatorial) and bis-rearranged: proximal 70a (ax,ax); 71a (ax,eq) and 72a,b (eq,eq) and distal 73a,b (eq,eq).

All products adopt a cone conformation, even when the starting calixarenes were not in cone conformations (as 65a,b), but were in paco (as 66a,b) or 1,3-alt conformation (as 67a,b). In the 
case of mono-rearranged products, the remaining $O$-carbamate group is stable (as in 69a,b) or may undergo hydrolysis to form the hydroxyl group (as in $\mathbf{6 8 a}, \mathbf{b}$ ).

The rearrangement proceeds via an intermediate five-membered ring. In the case of monorearrangement, the deprotonation by LDA affords a carbanion, which attacks the carbonyl of the ortho (adjacent) $O$-carbamate group, to form a five-membered ring. The subsequent quenching of the reaction mixture completes the migration, affording compound bearing at one meso position the amide group. For cone $\mathbf{6 5 a}$, the formation of five-membered ring in the intermediate $\mathbf{7 4}$, leading to axial mono-rearranged product $\mathbf{7 5}$, is presented. The bis-rearrangement proceeds via two five-membered intermediates.

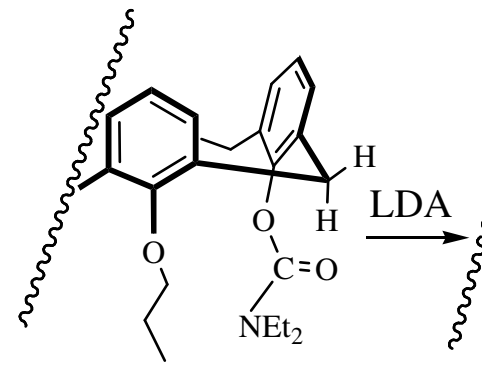

fragment of cone $\mathbf{6 5 a}$
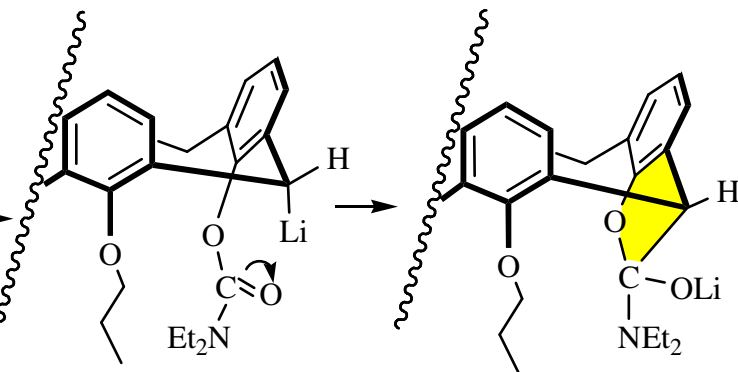

74

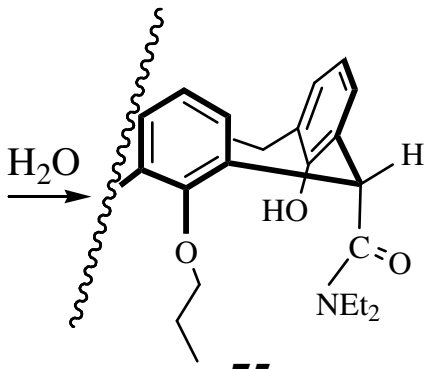

75

It should be pointed out that the above Fries rearrangement proceeds readily and the obtained calixarenes containing amide groups at meso positions undergo further reactions; as examples those of 70a and 73a are shown.

In 70a the existence of two axial amide groups in proximal positions allows the reaction with $n$-propyl bromide in the presence of $\mathrm{K}_{2} \mathrm{CO}_{3}$ affording 76, and the reaction with acetic acid yielding bis-lactone $\mathbf{7 7}$. This behavior of $\mathbf{7 0 a}$ results from the close proximity of two axial amide groups, which increases the acidity of the hydroxyl groups.
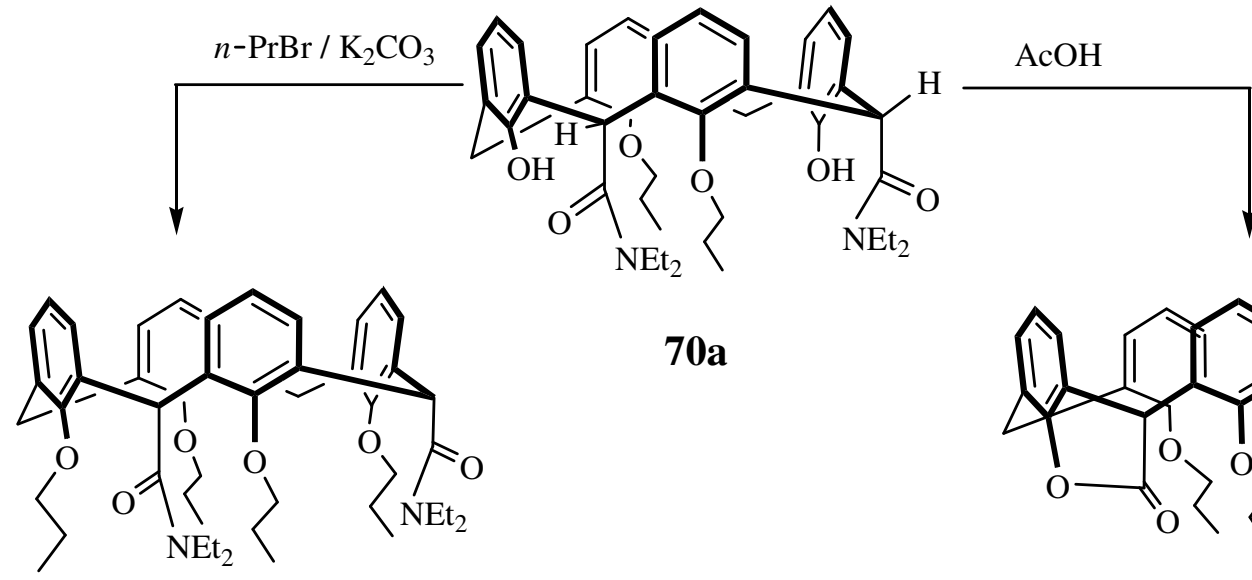

70a

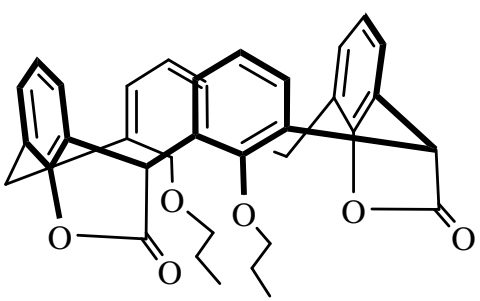

77 
It is noteworthy that in 73a, bearing two equatorial amide groups in distal positions, the propylation in the presence of $\mathrm{K}_{2} \mathrm{CO}_{3}$ would be impossible, instead $\mathrm{NaH}$ is required. The propylation of 73a in the presence of $\mathrm{NaH}$ affords $\mathbf{7 8}$ which by reduction with diborane yields the diamine $79 .^{37}$

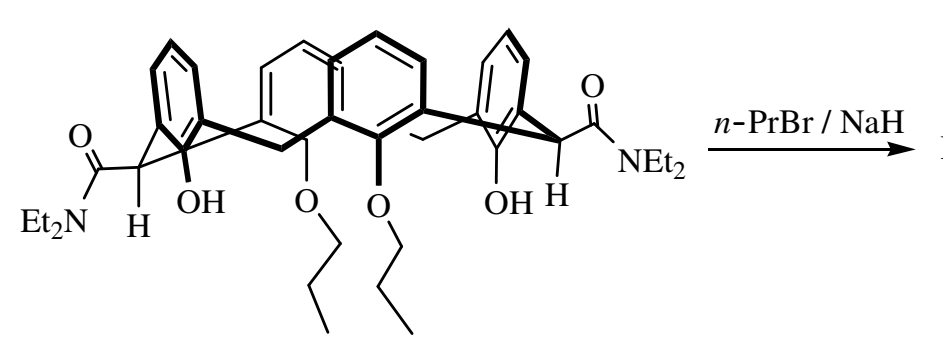

73a

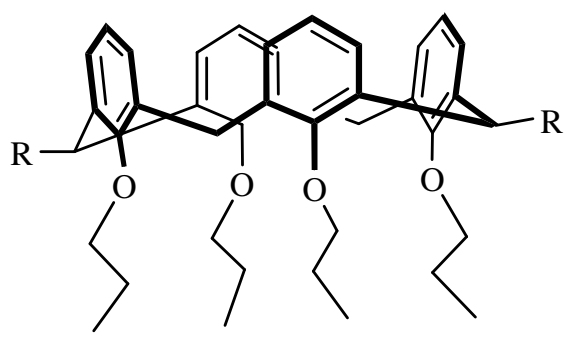

$78 \mathrm{C}(\mathrm{O}) \mathrm{NEt}_{2}$
$79 \mathrm{CH}_{2} \mathrm{NEt}_{2} \longleftarrow \mathrm{B}_{6} / \mathrm{THF}$

The conformational analysis of trans-disubstituted calixarenes 80a-c has shown that in 80a $\left(\mathrm{R}=\mathrm{Me}\right.$ ) the cone and 1,2-alt conformations coexist in $\mathrm{CDCl}_{3}$, however in calixarenes $\mathbf{8 0 b}$ and 80c bearing more bulky substituents ( $\mathrm{R}=i$ - $\mathrm{Pr}$ and $t$ - $\mathrm{Bu}$, respectively) the 1,2-alt conformation is preferred. $^{38}$

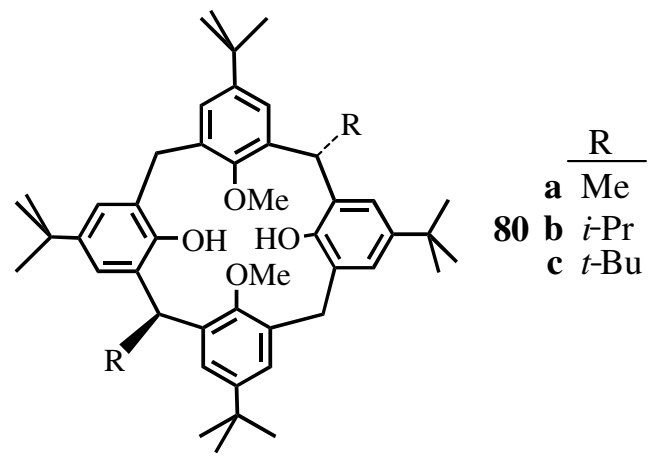

A single crystal of $\mathbf{8 1}$, grown from acetonitrile was investigated by X-ray diffraction. Calixarene 81 crystallizes with two MeCN molecules, one of them being situated inside the cavity. It was found that $\mathbf{8 1}$ adopts a cone conformation and exists in the crystal and in polar solvents as a zwitterion 82, with the axial dimethylamino group protonated and one hydroxyl group deprotonated. ${ }^{39}$ 


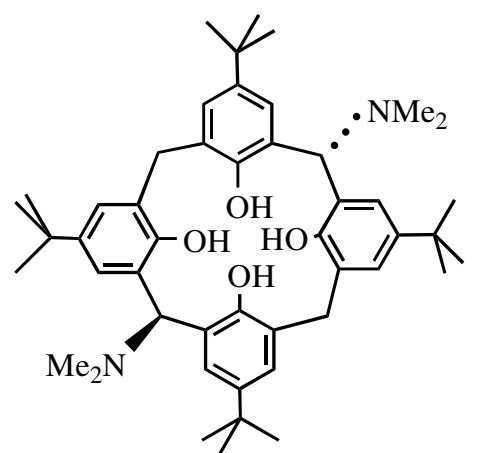

81

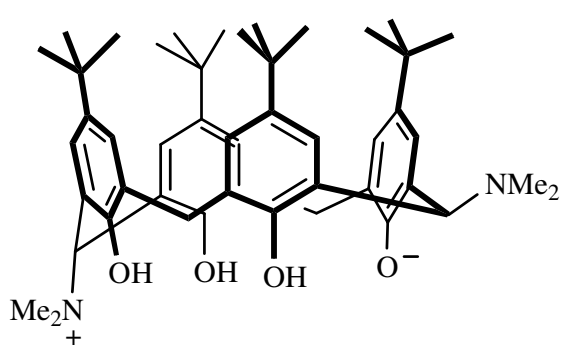

82

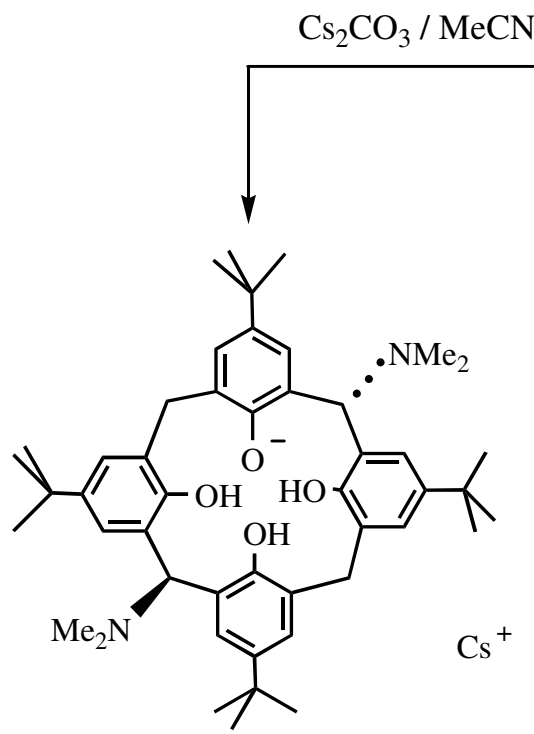

83

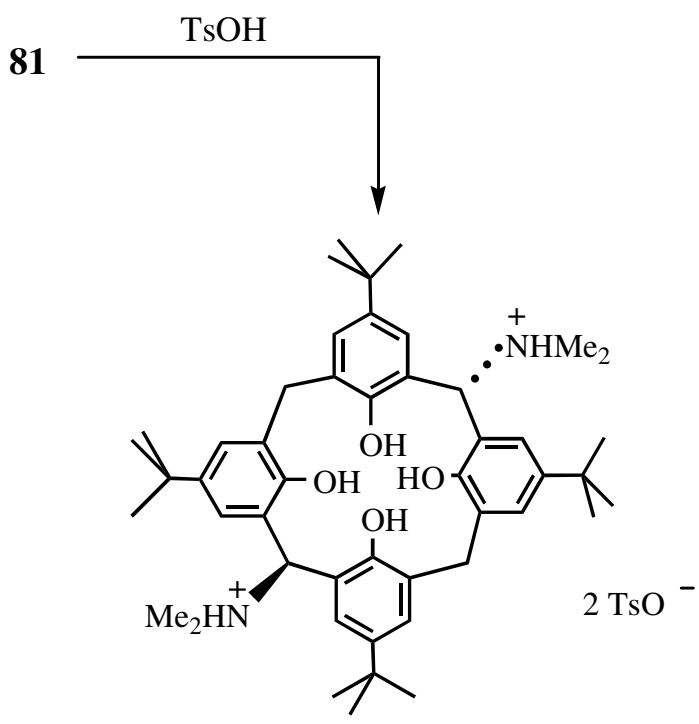

84

For ${ }^{1} \mathrm{H}$ NMR examination of $\mathbf{8 1}$, the model compounds $\mathbf{8 3}$ (with both dimethylamino groups nonprotonated) and $\mathbf{8 4}$ (with both dimethylamino groups protonated) have been synthesized. The reaction of $\mathbf{8 1}$ with $\mathrm{Cs}_{2} \mathrm{CO}_{3}$ in acetonitrile afforded $\mathbf{8 3}$, and reaction with $p$-toluenesulfonic acid yielded 84. The measurement of ${ }^{1} \mathrm{H}$ NMR spectra has confirmed the existence of 81 as a zwitterion 82 in $\mathrm{THF}^{39}$

\section{Calixarenes substituted at all meso positions}

The functionalization reactions of calixarenes proceeding at all meso positions will be described for calix[ $n]$ arenes, where $n=4,5$ and 6 . Then the direct synthesis of chiral meso substituted calixarenes will be shown.

It was found that calix $[n]$ arenes $(n=4,5,6), \mathbf{8 5 a}-\mathbf{c}$, upon photochemical bromination afford calixarenes $86 \mathbf{a}-\mathbf{c}$ substituted at all meso positions by bromine atoms. ${ }^{40-42}$ Reactions of calixarenes 86a-c with $\mathrm{O}-, \mathrm{N}$ - and $\mathrm{C}$ - nucleophiles involve replacement of bromine atoms by 
nucleophiles, leading to calixarenes $\mathbf{8 7 a}-\mathbf{c}$ functionalized at all meso positions. These reactions proceed in alcohols used as solvents or may require ionizing solvents, such as 2,2,2trifluoroethanol (TFE) or hexafluoro-2-propanol (HFIP). ${ }^{40-42}$

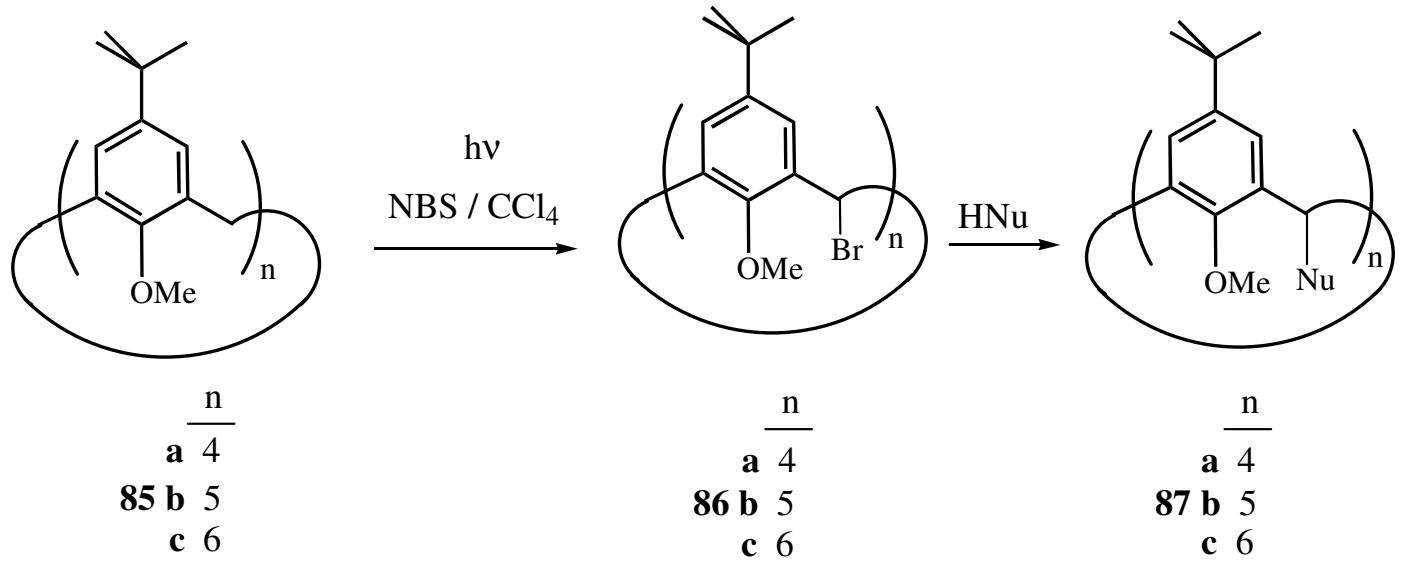

- Functionalization of calix[4]arenes at all meso positions

The solvolysis of 86a with TFE (=2,2,2-trifluoroethanol), performed in the absence of an additional nucleophile or a Lewis acid, yielded 88, and when carried out with EtOH/TFE 1:1 mixture, gave 89. The reaction of $\mathbf{8 6 a}$ with $\mathrm{NaN}_{3}$ in the presence of TFE or HFIP yielded $\mathbf{9 0} .^{43}$ 


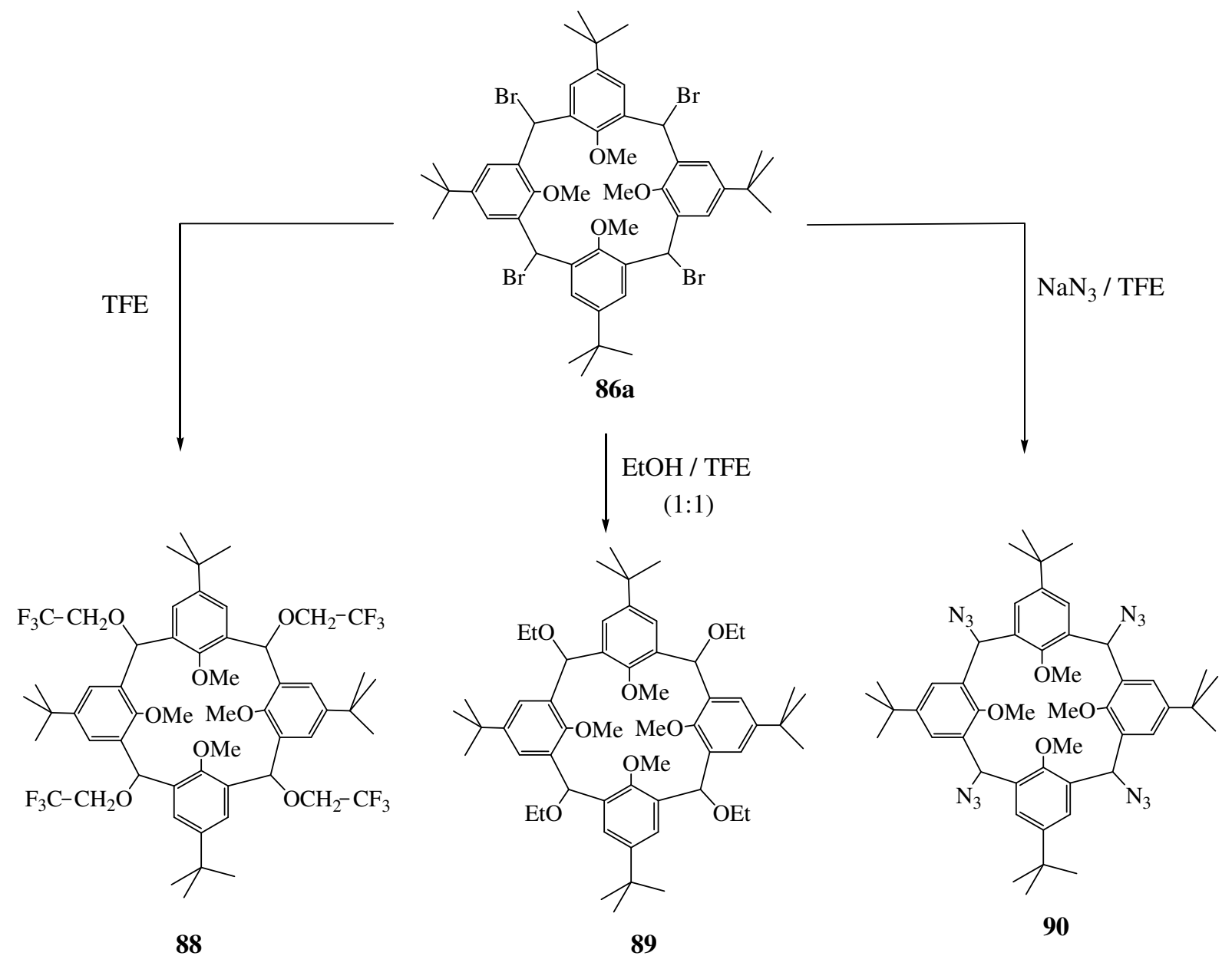

In a similar procedure 86a reacted with $n-\mathrm{PrOH}, i-\mathrm{PrOH}$ and ethylene glycol.

Solvolysis of 86a in $\mathrm{AcOH}$ yielded 91 which upon reduction of acetoxy groups gave calixarene 92 bearing hydroxyl groups at all meso positions. ${ }^{40}$

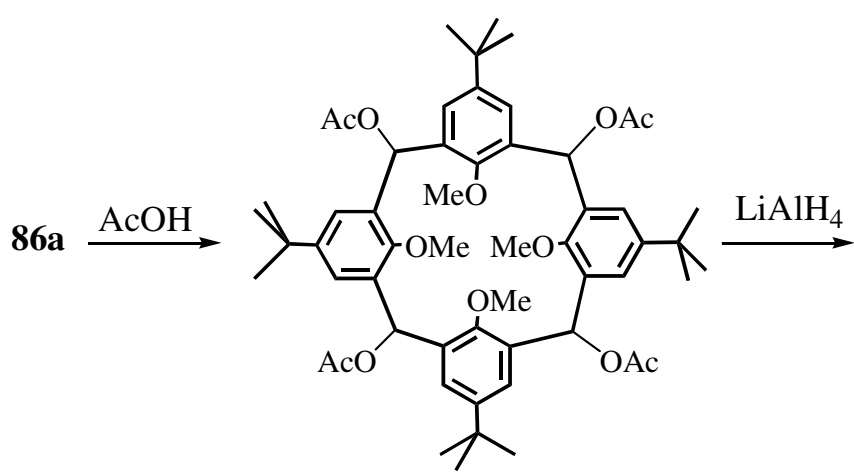

91

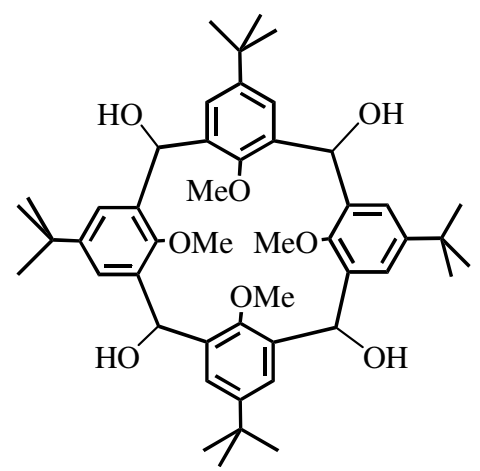

92 
The solvolytic Friedel-Crafts reaction of 93 (obtained from the corresponding calixarene by similar bromination with NBS) with 2-methylfuran, performed with the use of 1,2-butylene oxide as a $\mathrm{HBr}$ scavenger, afforded $94 .^{43}$

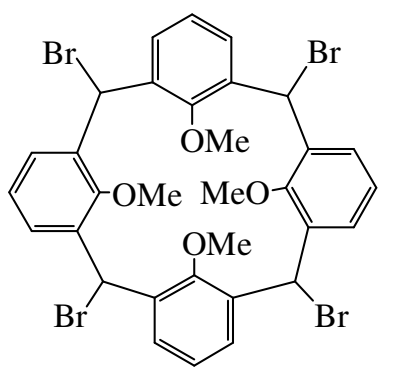

93
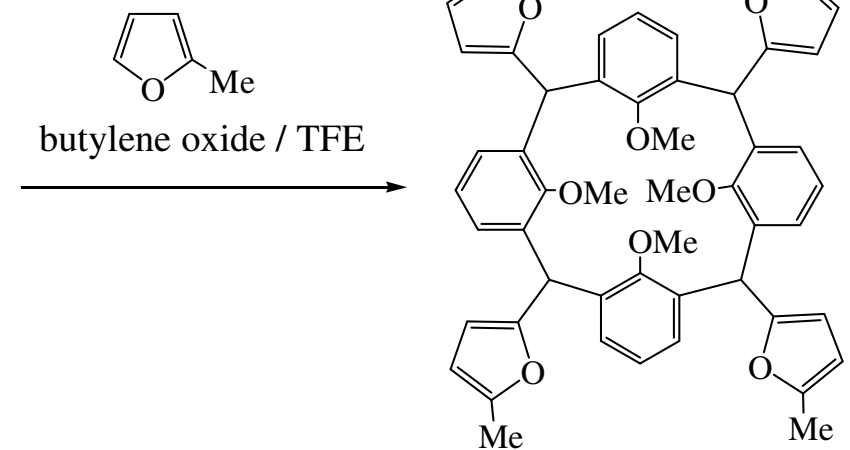

94

- Functionalization of calix[5]arenes at all meso positions

Replacement of bromine atoms in $\mathbf{8 6 b}$ by nucleophiles affords calixarenes $\mathbf{8 7 \mathbf { b }}$. It was found that the reactions with TFE and 2-propanol proceed by refluxing $\mathbf{8 6}$ b with these alcohols, however in the case of propargyl alcohol, $m$ - and $p$-xylenes and $p$-t-butylphenol, the use of HFIP is necessary. ${ }^{41}$

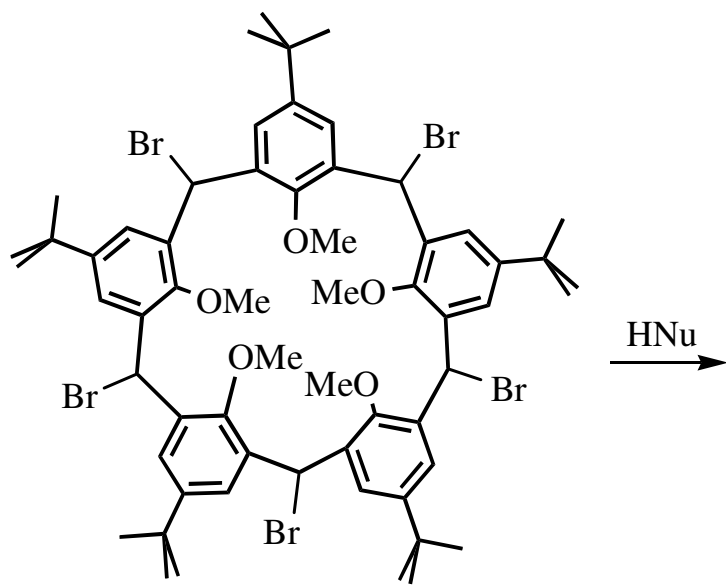

86b

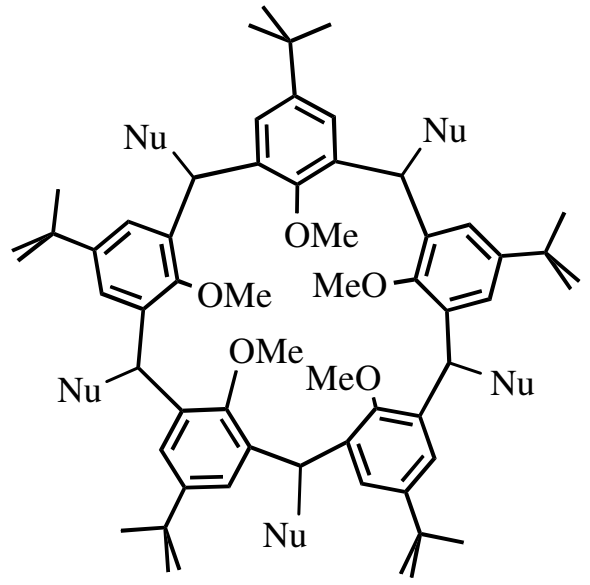

87b<smiles>Cc1ccc(C)c(C)c1</smiles> 
One should point out the importance of calix[5] arene derivatives functionalized at meso positions; their cavity is larger than that of functionalized calix[4]arenes, but in contrast to larger calixarenes they still adopt nearly symmetric cone conformations.

- Functionalization of calix[6]arenes at all meso positions

Calixarene 86c was refluxed in alcohols $\mathrm{MeOH}, \mathrm{EtOH}, n-\mathrm{PrOH}, i-\mathrm{PrOH}, n-\mathrm{BuOH}$ to give products 87c substituted at all meso positions by alkoxy groups. Refluxing of 86c in TFE yielded 86c $\left(\mathrm{Nu}=\mathrm{OCH}_{2} \mathrm{CF}_{3}\right)$, and refluxing of 86c with ethylene glycol in TFE afforded 87c $(\mathrm{Nu}=$ $\left.\mathrm{OCH}_{2} \mathrm{CH}_{2} \mathrm{OH}\right) .{ }^{42}$ Reactions of $86 \mathbf{c}$ with $m$ - and $p$-xylenes and with mesitylene leading to products 87c substituted at all meso positions by aryl groups were carried out in HFIP.

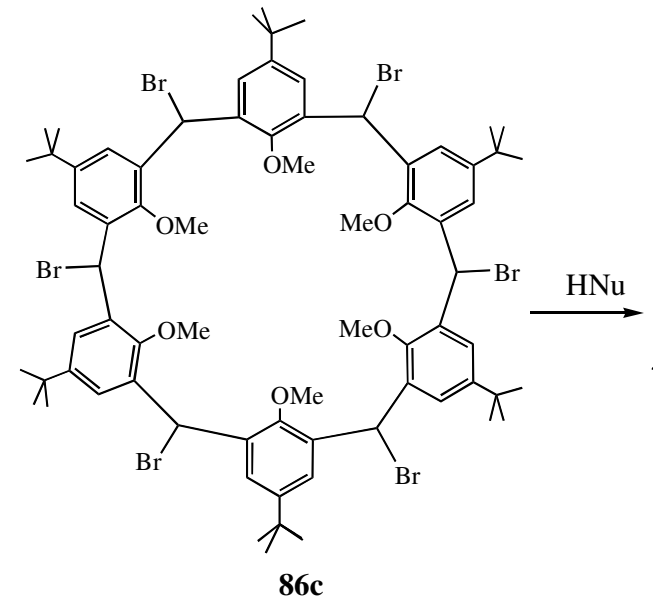

$86 \mathrm{c}$

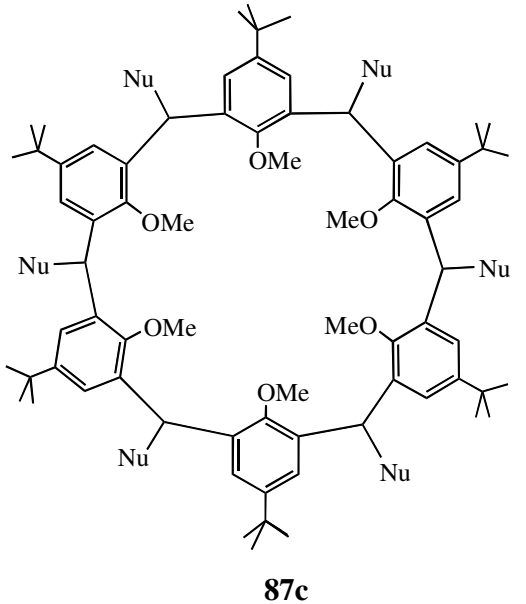

$87 \mathrm{c}$

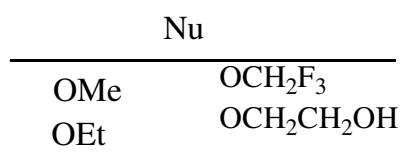

$\mathrm{O}-n-\mathrm{Pr}$

$\mathrm{O}-i$ - Pr

$\mathrm{O}-n-\mathrm{Bu}$

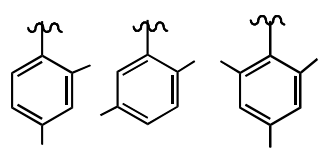

Reactions of 86c with sodium azide and with aniline performed in TFE, lead to calixarenes 87c $\left(\mathrm{Nu}=\mathrm{N}_{3}\right)$ and 87c $(\mathrm{Nu}=\mathrm{HNPh})$, respectively. Acetolysis of 86c afforded 87c $(\mathrm{Nu}=\mathrm{OAc})$ which upon $\mathrm{LiAlH}_{4}$ reduction yielded 87c $(\mathrm{Nu}=\mathrm{OH})$. It is worth noting that the presence of substituents at meso positions of $87 \mathrm{c}$ rigidifies the calixarene structure.

Calixarene $\mathbf{8 8}$ with all four meso positions monosubstituted by phenyl groups has been obtained from tetraketocalixarene $\mathbf{8 9} \mathbf{b} .{ }^{44}$ The synthesis begins with the reaction of $\mathbf{8 9 b}$ with PhLi. The starting tetraketocalixarene 1,3-alt 89b was obtained by methylation of 89a; this protection of the hydroxyl groups of 89a was necessary to avoid the acid-base reactions of these hydroxyl groups with PhLi. 


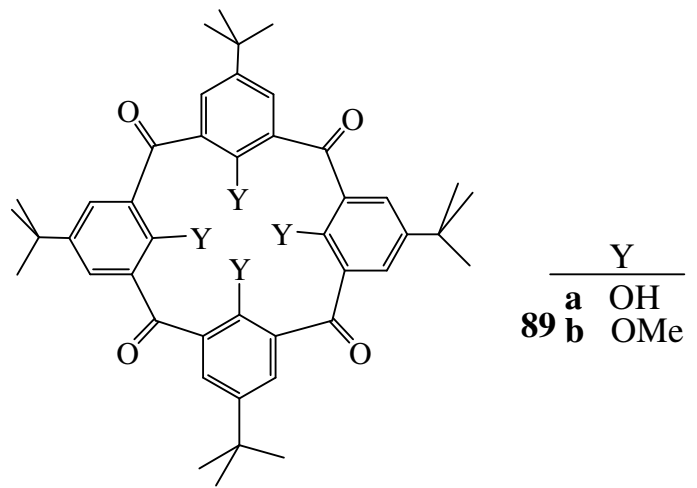

The reaction of 89b with $\mathrm{PhLi}$ in THF afforded trans di-addition product 90; with the excess of $\mathrm{PhLi}$, the tetra-addition product $\mathbf{9 1}$ was obtained as a mixture of four isomers $r c c c, r c c t, r c t t$ and $r t c t$, which upon recrystalization gave one product, $91(r c c c)$. The next step was the reduction of the four hydroxyl groups in 91, performed with $\mathrm{Et}_{3} \mathrm{SiH} / \mathrm{CF}_{3} \mathrm{COOH}$ to give $\mathbf{8 8}$. ${ }^{44}$

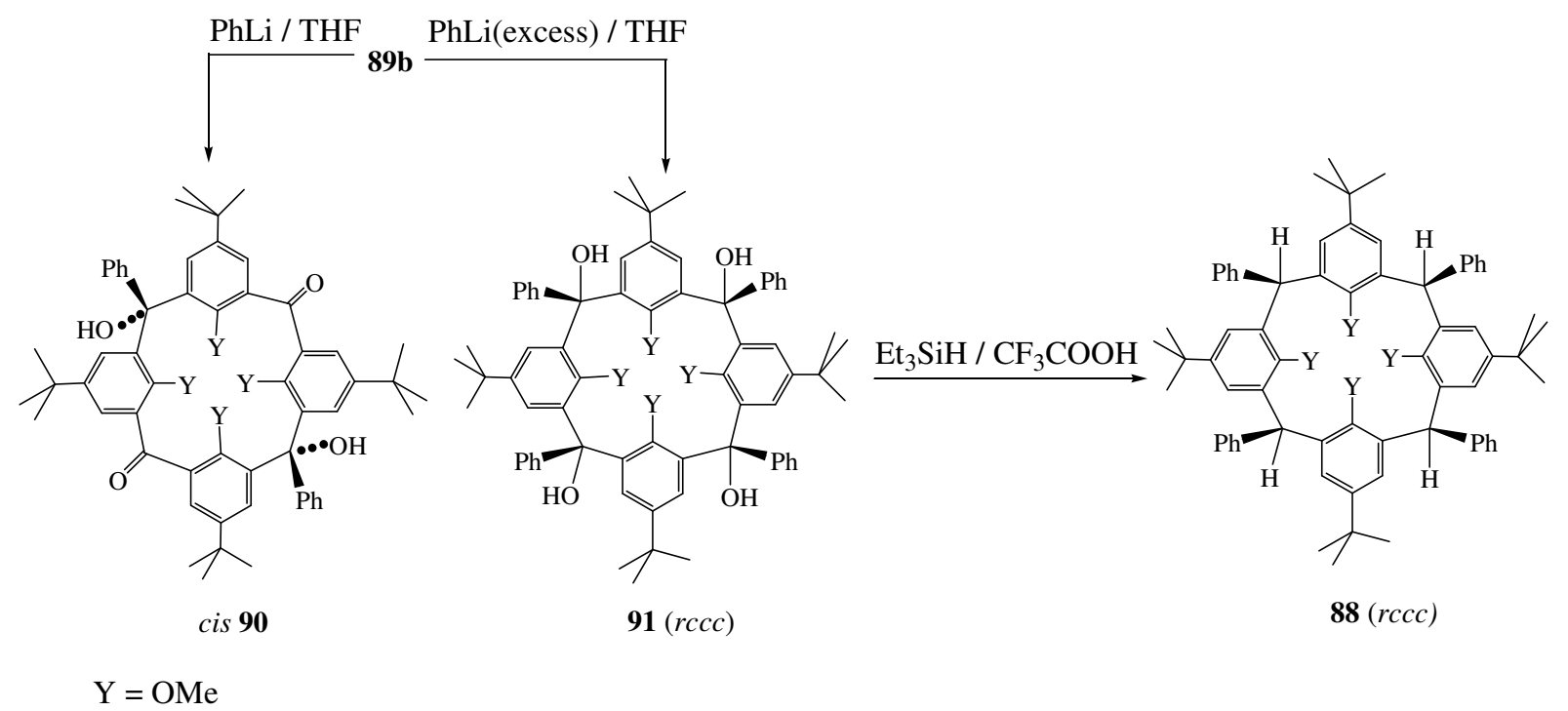

It was found that $\mathbf{8 8}$ has all cis, i.e. the rccc form; $\mathbf{8 8}$ in the crystal adopts the 1,3-alt conformation. Calixarene $\mathbf{9 2}$ which is an isomer of $\mathbf{8 8}$ has the $r c c t$ form; $\mathbf{9 2}$ in the crystal also adopts the 1,3-alt conformation. Examination of the X-ray structures of $\mathbf{8 8}$ and $\mathbf{9 2}$ shows that in the 1,3-alt conformation their methoxy groups, intramolecularly hydrogen bonded to neighboring hydroxyl groups are pointing toward the cavity (orientation "in"). ${ }^{44}$ 


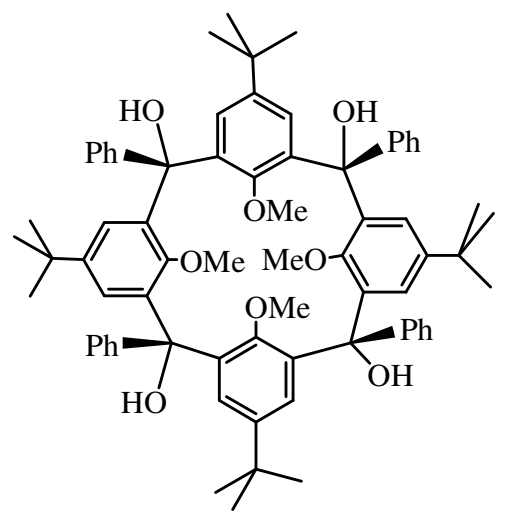

$\mathbf{8 8}($ rccc $)$

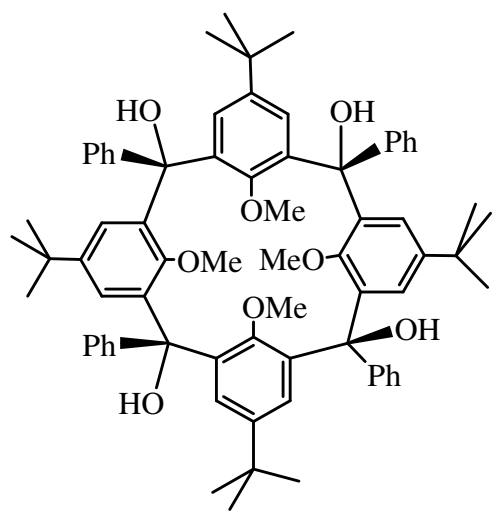

$92(r c c t)$

When 88 is dissolved in acetone- $d_{6}$, the hydroxyl protons exchange with the deuterium atoms present in residual water of the solvent. The analysis of the ${ }^{1} \mathrm{H}$ NMR (400 MHz) spectrum of 88 in acetone- $d_{6}$ differs from that in $\mathrm{CDCl}_{3}$. This behavior results from isotopic perturbation of the conformational equilibrium in 88. Several species (isotopomers) of a different number and positions of the OD groups are possible for $\mathbf{8 8}^{45}$

An attention should be paid also to the method allowing a direct construction of mesosubstituted chiral calixarenes in which the chirality results from the substitution of meso positions. ${ }^{46}$ This method is highly valuable, having in mind that among syntheses of calixarenes substituted at meso positions, the approach to chiral species is rare.

The synthetic procedure is similar to the shown below annulation of the biscarbene complex $\mathbf{9 3}$ with diyne 94, leading to calixarene 95; in this reaction new rings of the product were built. ${ }^{47-50}$<smiles>COC(=O)C=CCc1cc(C)cc(CCC(=CC=CC(=C=O)OC)OC)c1OC</smiles><smiles>C#CCc1cc(C)cc(CC#C)c1OC</smiles>

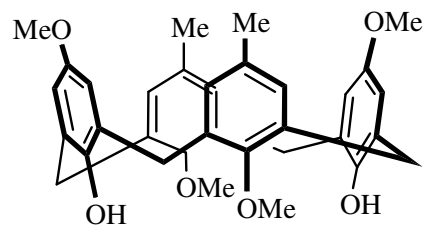

95 
The formed calixarene 95 is meso-unsubstituted, however the substitution of one or both methylene groups in $\mathbf{9 3}$ and/or $\mathbf{9 4}$ allows to obtain the desired meso-functionalized calixarenes. ${ }^{46}$

Biscarbene complexes: unsubstituted 96a, $(\mathrm{X}=\mathrm{H})$ and disubstituted 96b $(\mathrm{X}=\mathrm{OMe})$ and diynes: $(R, R)-97$ (X=OMe), $(S, S)-97(\mathrm{X}=\mathrm{OMe})$ and $(R, R)-98(\mathrm{X}=\mathrm{OTBS})$ served as starting compounds.<smiles>[X]C(=CC(=CC(=O)OC)OC)OC</smiles>

biscarbene complexes

$$
96 \begin{aligned}
& \text { a } \\
& \text { b }
\end{aligned}
$$<smiles>[X]C(C#C)c1cc(C)cc(C([X])C#C)c1OC</smiles>

diynes

97<smiles>C#C[C@H](OC)c1cc(C)cc([C@@H](C#C)OC)c1OC</smiles><smiles>C#C[C@H](OC)c1cc(C)cc([C@@H](C#C)OC)c1OC</smiles>

$(S, S)-97(\mathrm{X}=\mathrm{OMe})$

$$
(R, R)-97(\mathrm{X}=\mathrm{OMe})
$$<smiles>C#C[C@H](O)c1cc(C)cc([C@@H](C#C)O[Na])c1OC</smiles>

$$
\mathrm{TBS}=t-\mathrm{BuMe}_{2} \mathrm{Si}-
$$

$(R, R)-98(\mathrm{X}=\mathrm{OTBS})$

Synthesis of calixarenes, substituted at two meso positions:

The reaction of $96 \mathrm{a}$ with diyne $(R, R) 97(\mathrm{X}=\mathrm{OMe})$ afforded the mixture of cone and paco conformers of calixarene 99, substituted at two meso positions, the major species being cone $\mathbf{9 9}$. Similarly the reaction of $96 \mathrm{a}$ with diyne $(R, R) 98$ (X=OTBS) afforded the mixture of cone and paco conformers of calixarene 100, the major product being cone 100. Upon removal of the TBS group from 100, the calixarene $(S, S)$ 101, substituted at two meso positions, existing exclusively as cone conformer was obtained. 


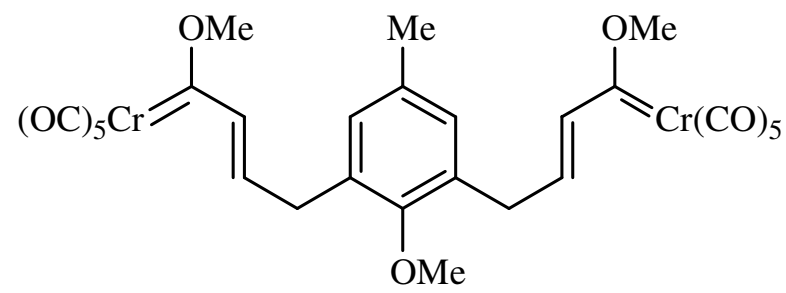<smiles>[X]C(C#C)c1cc(C)cc([C@H]([Z])C#CCCOC(C)(C)C)c1OC</smiles>
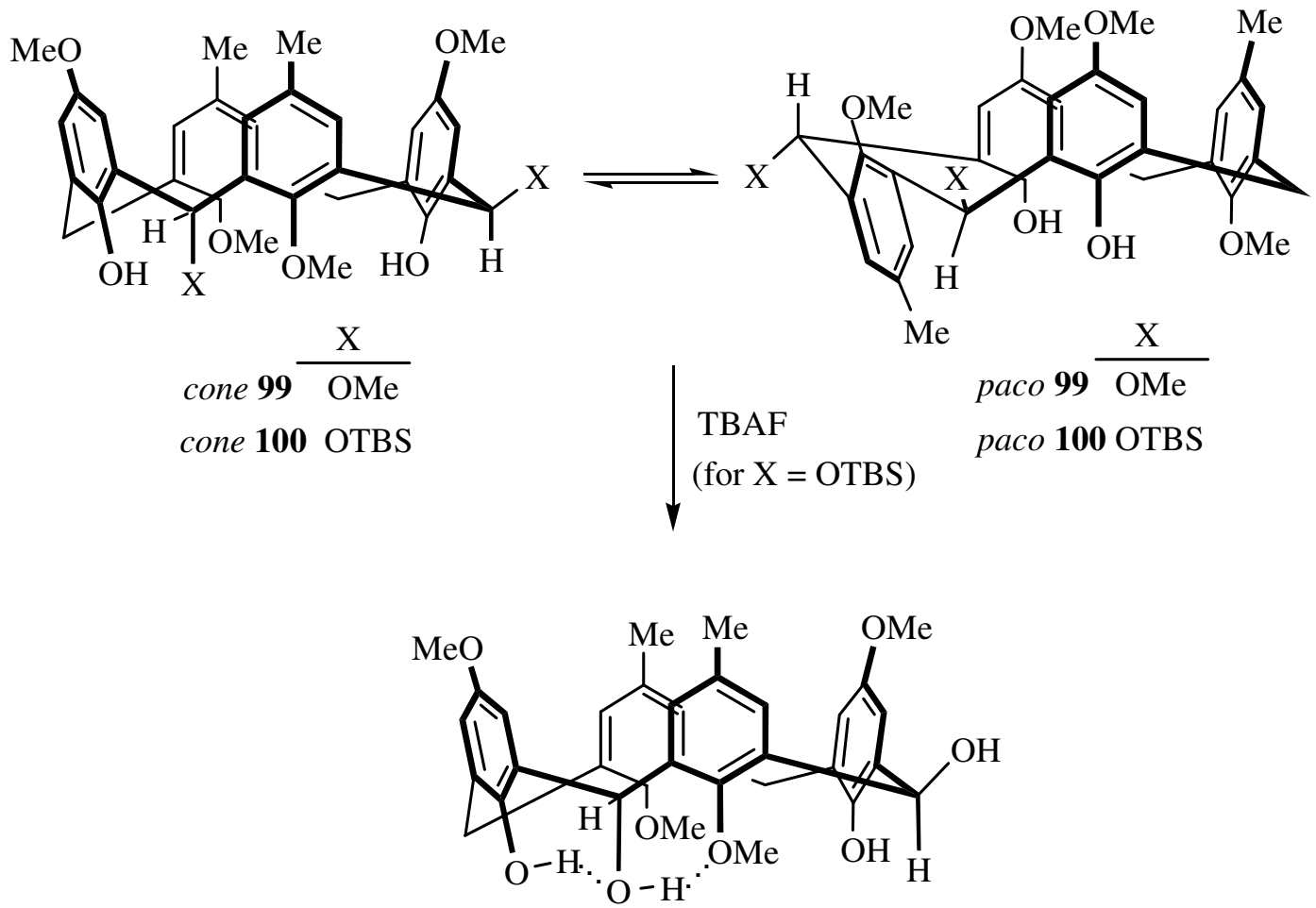

(S,S)-101

Synthesis of calixarenes substituted at four meso positions:

The biscarbene complex $96 \mathrm{~b}$ reacts with diyne $(R, \mathrm{R})-\mathbf{9 7}$ to give meso tetrasubstituted calixarene $(S, S, S, S) \mathbf{1 0 2}$ existing as a single cone conformer and reacts with diyne $(S, S)$-97 affording, as expected, optically inactive (meso)-103. 


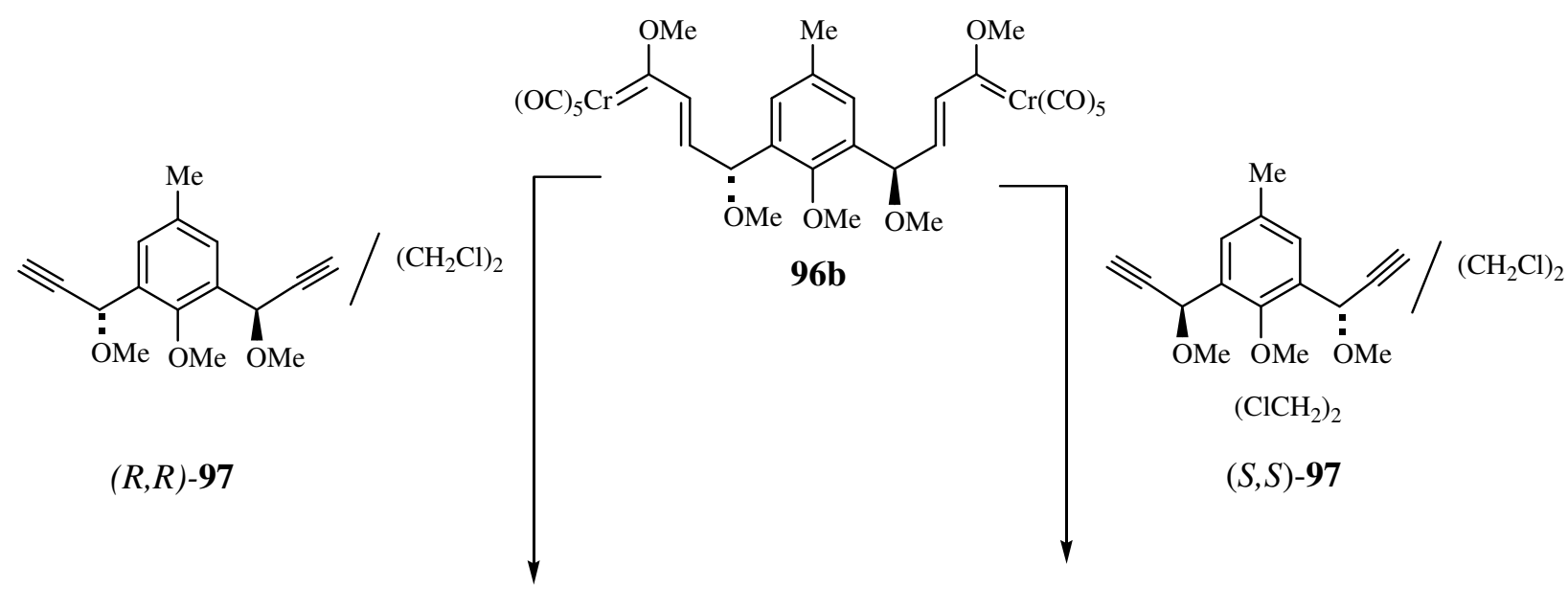

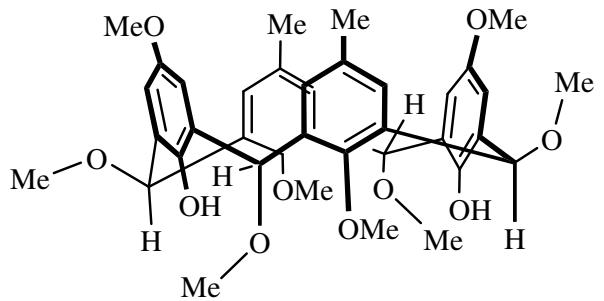

$(S, S, S, S)-\mathbf{1 0 2}$

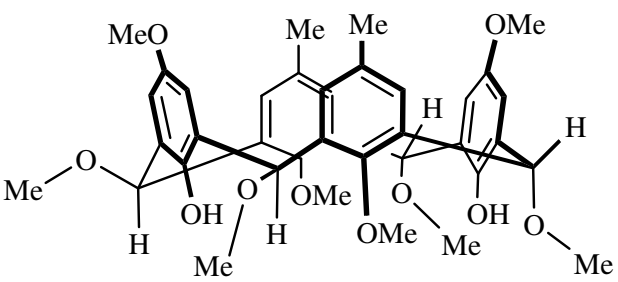

(meso)-103

In conclusion, the above syntheses are an interesting approach to chiral calixarenes substituted at two and at all meso positions. ${ }^{46}$

\section{Ketocalixarenes}

Ketocalixarenes are a class of compounds which may be regarded as calixarenes functionalized by carbonyl groups situated at their meso positions; they are interesting as synthons for various target products, among them meso-substituted calixarenes. Selected examples of syntheses and reactivity of ketocalixarenes are described below.

The synthesis of ketocalixarenes may be achieved by oxidation of calixarene $\mathbf{1 0 4 b}$ at the meso positions using $\mathrm{CrO}_{3}$. In contrast to $104 \mathbf{a}$, the starting calixarene $104 \mathbf{b}$ containing four acetate groups is conformationally rigid, because the rotation of the rings through the annulus is blocked by the bulky acetate substituents. Therefore $\mathbf{1 0 4 b}$ exists as different atropoisomers rather than the usual types of conformers.

The acetylation of 104a afforded the starting calixarene $104 \mathrm{~b}$ as a mixture of paco $\mathbf{1 0 4 b}$ and 1,3-alt 104b. This atropoisomeric mixture upon treatment with $\mathrm{CrO}_{3}$ in boiling $\mathrm{Ac} c_{2} \mathrm{O} / \mathrm{AcOH}$ yielded a mixture of paco 105 (from paco 104b) and 1,3-alt 106 (from 1,3-alt 104b), which could be separated by fractional crystallization. The basic hydrolysis of paco $\mathbf{1 0 5}$ afforded paco diketocalixarene $\mathbf{1 0 7}$ with the carbonyl groups in cis positions. ${ }^{51}$ 


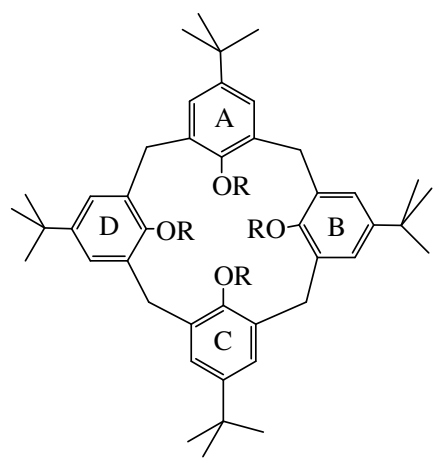

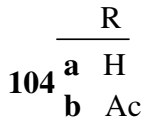

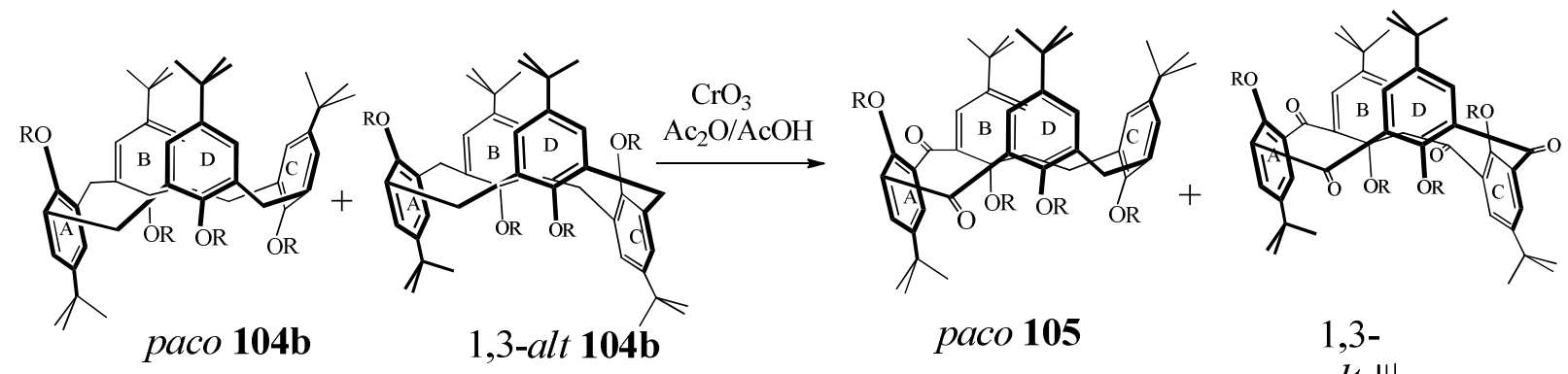

$\mathrm{R}=\mathrm{Ac}$

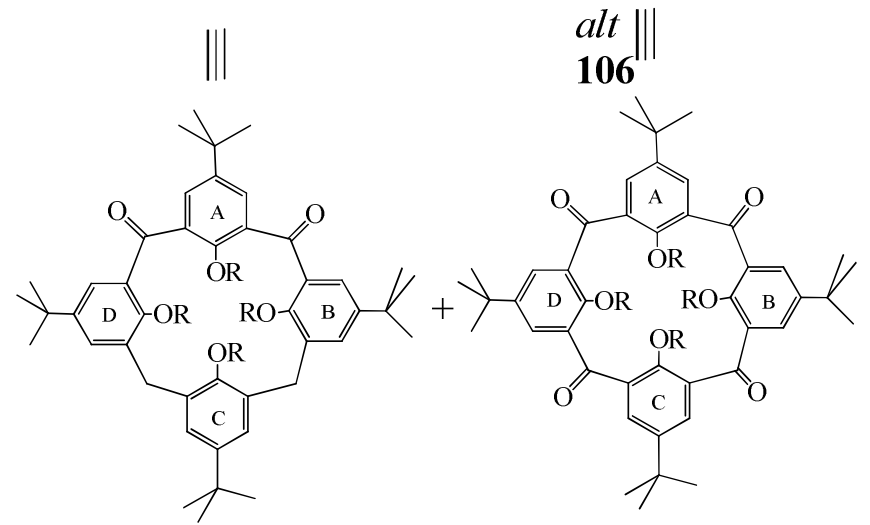

paco 107

During $\mathrm{CrO}_{3}$ oxidation it was found that the rotation of the aryl rings through the annulus does not occur, and that only meso positions connected to geminal rings anti, i.e. rings pointing to opposite directions can be oxidized; the meso positions which are between rings syn, i.e. rings pointing out to the same direction, cannot be oxidized.

Therefore, paco $\mathbf{1 0 4 b}$, in which only two methylene groups connected with the ring $\mathbf{A}$ are located between anti rings, are oxidized to give diketocalixarene paco 105, whereas 1,3-alt 104b, in which all methylene groups are located between rings anti, is oxidized to tetraketocalixarene 1,3 -alt $106 .^{51}$ 

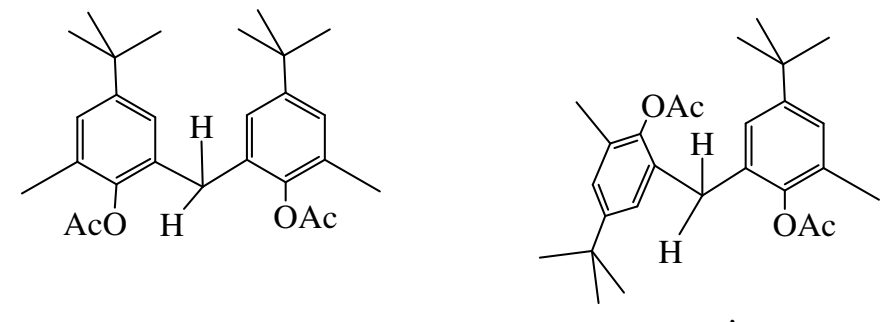

syn

anti

(no oxidation)

(oxidation occurs)

In order to obtain diketocalixarene with carbonyl groups in trans positions, the mixture of 1,2-alt 104b and 1,3-alt 104b (9:1) was oxidized with $\mathrm{CrO}_{3}$ to give 1,2-alt $\mathbf{1 0 8}$ (from 1,2-alt 104b) and 1,3-alt 106 (from 1,3-alt 104b). The basic hydrolysis of 1,2-alt 108 yielded 1,2-alt 109. ${ }^{51}$

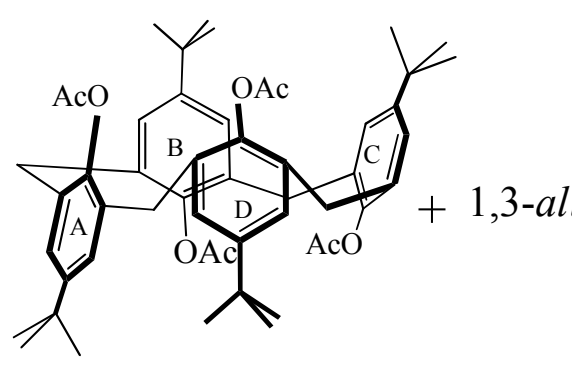

$1,2-$ alt 104b

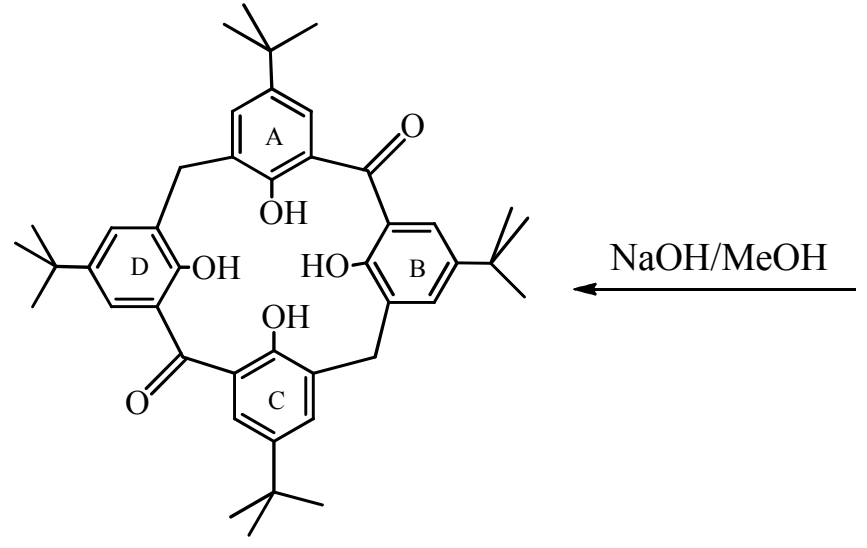

$\mathrm{CrO}_{3}$ $\mathrm{Ac}_{2} \mathrm{O} / \mathrm{AcOH}$

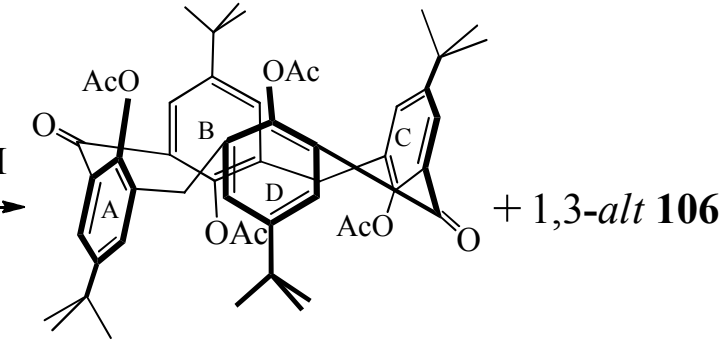

1,2-alt 108

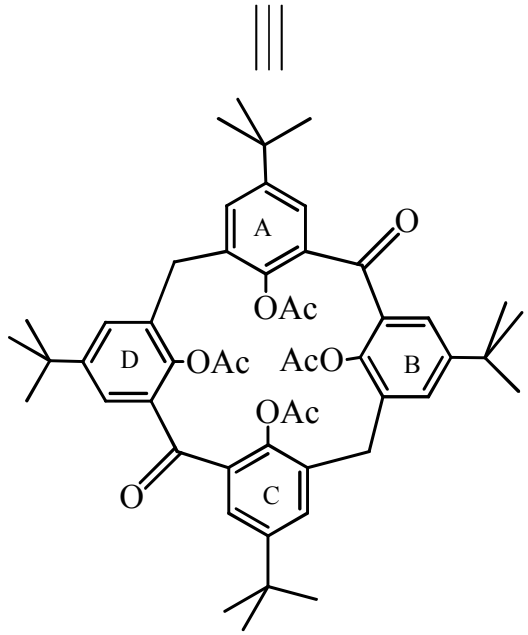

\section{1,2-alt 109}

Calixarene 110 was oxidized with $\mathrm{CrO}_{3}$ to give ketocalix[6]arene 111a which upon basic hydrolysis afforded ketocalix[6]arene 111b. This experiment was followed by the base-catalyzed methylation of 111b in order to obtain the ketocalixarene 111c. 

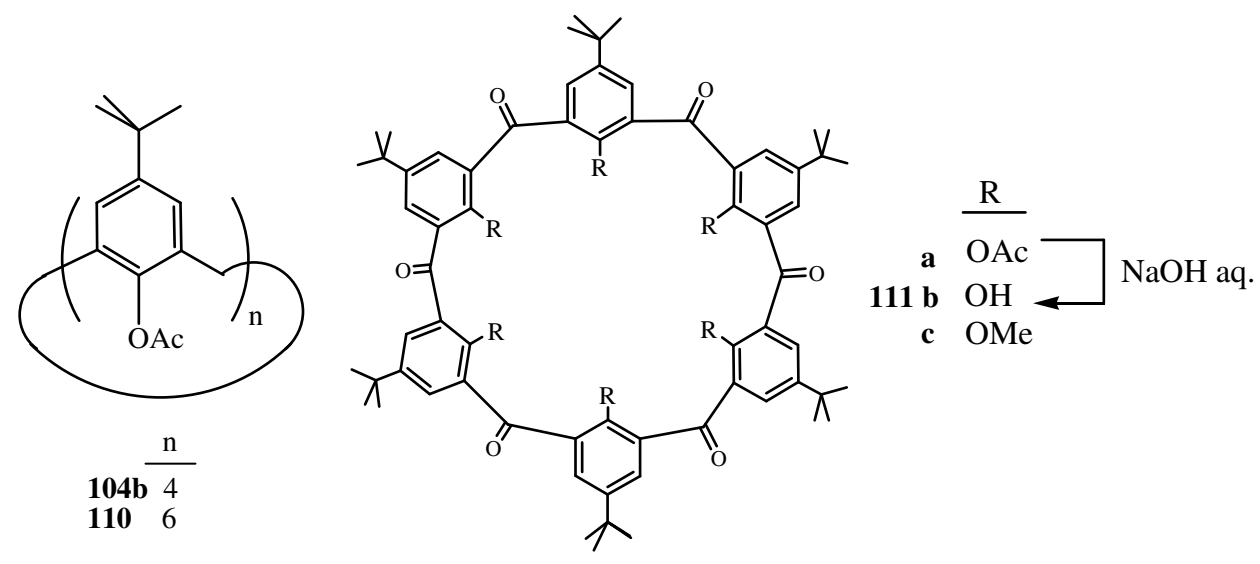

However, reaction of 111b with $\mathrm{MeI}$ in $\mathrm{MeCN}$ in the presence of $\mathrm{K}_{2} \mathrm{CO}_{3}$ as a base did not give the expected 111c, instead the monoxanthone calixarene 112 and three calixarenes 113a,b and 114 containing two xanthone moieties were obtained. ${ }^{52}$

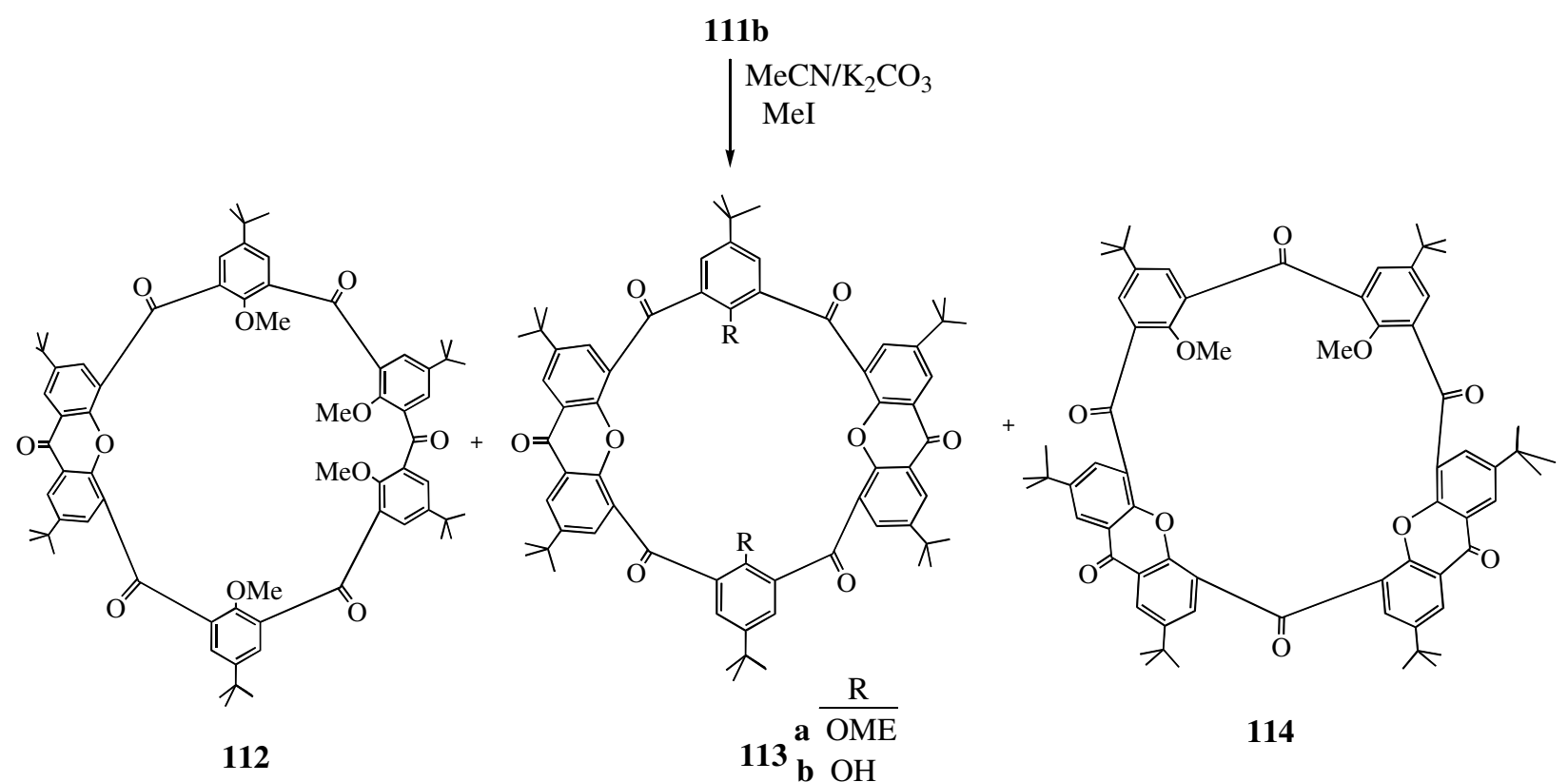

In the above process the formation of xanthone groups under methylation conditions is facilitated by the activating influence of the carbonyl groups which enables the intramolecular $\mathrm{S}_{\mathrm{N}} A r$ reaction between a methylated benzene ring and a neighboring phenolate serving as a nucleophile $(\mathbf{A} \rightarrow \mathbf{B} \rightarrow \mathbf{C})$. It should be pointed out that 111b is able to form such xanthone derivatives, whereas for lower calixarenes it would be impossible, since the large calixarene can better accomodate the increased strain resulting from the presence of the rigid xanthone group. 


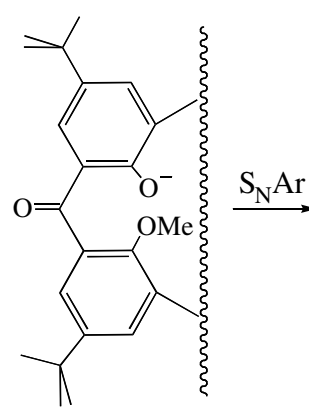

A

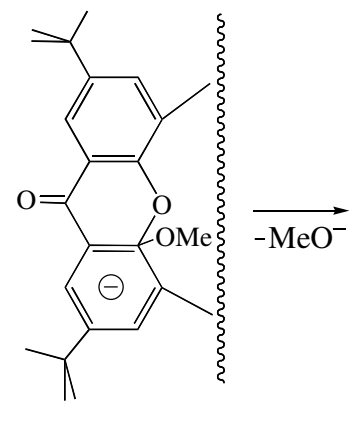

B

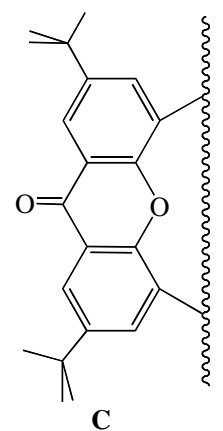

C

Using a large excess of MeI, dimethylacetamide as a solvent, and $\mathrm{Cs}_{2} \mathrm{CO}_{3}$ as a base, $\mathbf{1 1 1 b}$ could be converted into desired 111c. ${ }^{52}$

Studying the reactivity of ketocalixarenes it was found that tetraketocalixarene $\mathbf{1 1 5}$ upon treatment with excess $t$-BuLi yielded a complex mixture, with $\mathbf{1 1 6}$ as a major product. Recrystalization of the crude product from $\mathrm{CHCl}_{3} /$ acetone afforded a mixture of 116, di- $t$ butylated at two bridges, and 117, tri-t-butylated at three bridges. It should be emphasized that 116 and 117 are rare examples of calixarenes containing two different functionalities at the meso bridges. In the above reaction, one of the four methoxy groups of 115 was cleaved; compounds 116 and 117 bear only three methoxy groups at the narrow rim. Rotation of the $t$-butyl groups situated at the meso bridges in calixarenes 116 and $\mathbf{1 1 7}$ is restricted due to steric hindrance. ${ }^{53}$

By way of contrast, the rotation of $t$-butyl groups is not restricted in the cone calixarene 118 in which two opposite bridges are substituted by $t$-butyl groups. 


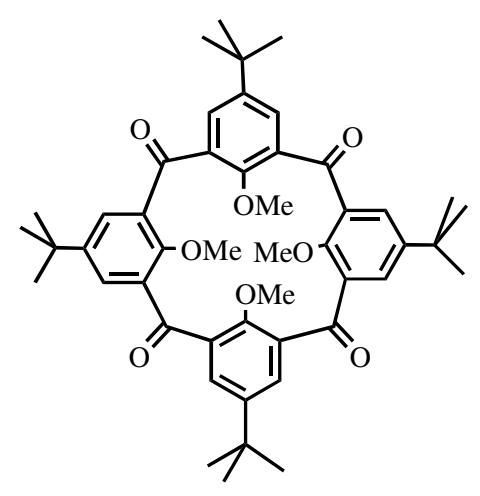

115

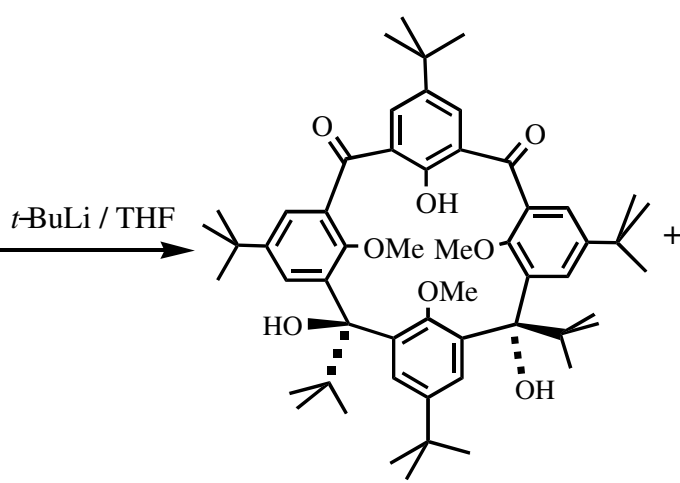

116

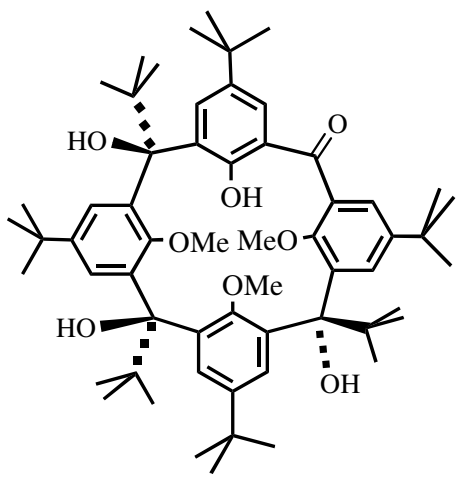

117<smiles>C=C(C)c1cc(Cc2cc(C(C)(C)C)cc([C@@H](c3cc(C(C)(C)C)cc(Cc4cc(C(C)(C)C)cc(C(c5cc(C(C)(C)C)cc(C(C)(C)C)c5O)c5cc(C(C)(C)C)cc(C(C)(C)C)c5O)c4O)c3O)C(C)(C)C)c2O)c(O)c(C(C)(C)C)c1</smiles>

118

Investigation of the dimethylation and dibenzylation reactions of tetraketocalixarene 119a has shown that they afford proximal (i.e. disubstituted in neighboring rings) products 119c and 119f. ${ }^{54}$ The result of these processes is other than in the case of the parent 22 which upon the same reactions affords distal, (i.e. disubstituted in opposite rings) products. 


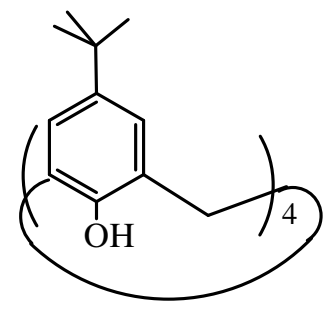

22

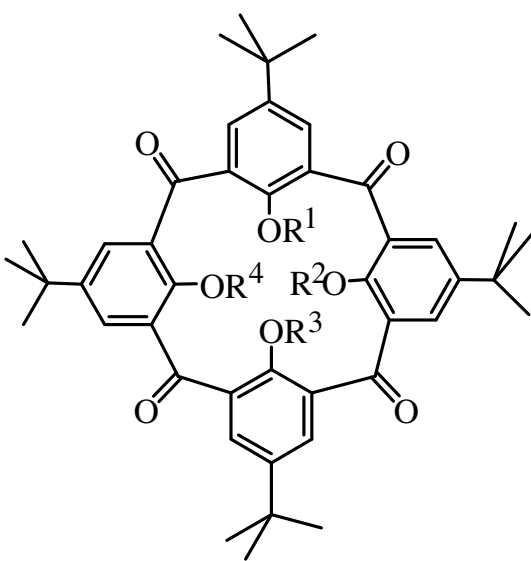

\begin{tabular}{lllll}
$\mathrm{R}^{1}$ & $\mathrm{R}^{2}$ & $\mathrm{R}^{3}$ & $\mathrm{R}^{4}$ \\
\hline $\mathbf{a}$ & $\mathrm{H}$ & $\mathrm{H}$ & $\mathrm{H}$
\end{tabular}

b $\mathrm{Me} \mathrm{H} \quad \mathrm{H} \quad \mathrm{H}$

c $\mathrm{Me} \mathrm{Me} \mathrm{H} \mathrm{H}$

119 d Me Me Me H

e $\mathrm{Me} \mathrm{Me} \mathrm{Me} \mathrm{Me}$

f $\mathrm{Bz} \mathrm{Bz} H \quad H$

g $\mathrm{Bz} \mathrm{Bz} \mathrm{Bz} \mathrm{Bz}$

119a-g

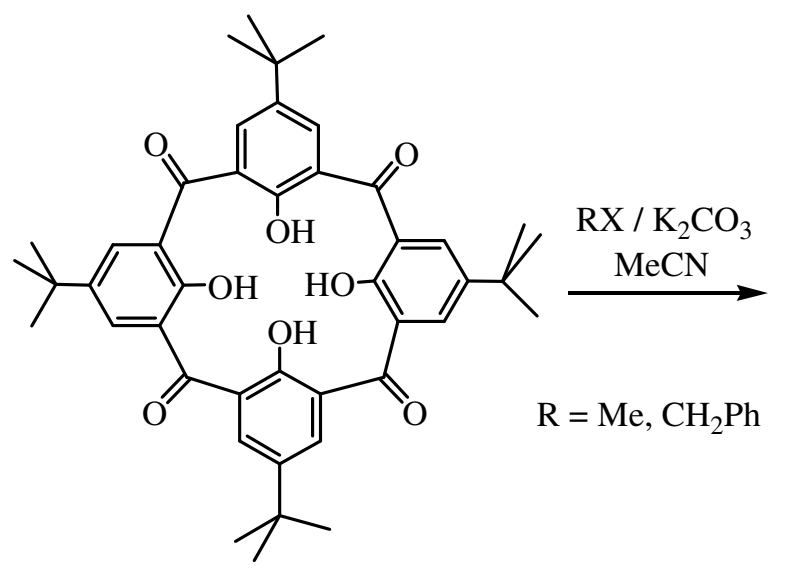

119a

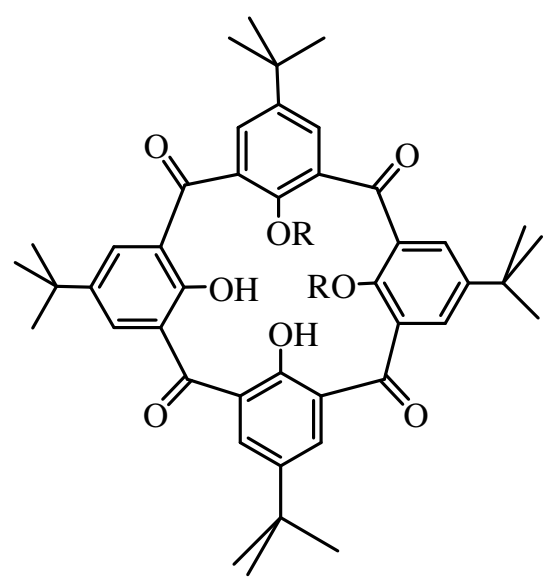

${ }_{119} \frac{\mathrm{R}}{\mathrm{c} \mathrm{Me}}$

The methylation products were mono- and di-substituted tetraketocalixarenes $119 \mathrm{~b}$ and 119c, respectively; the increased amount of a base gave rise to formation of tri- and tetramethylated compounds 119d and 119e. The benzylation afforded di- and tetrasubstituted products $119 \mathrm{f}$ and $119 \mathrm{~g}$, respectively.

In contrast to parent calixarene 22 which has the cone conformation, the tetraketocalixarene 119a, along with its substituted products $\mathbf{1 1 9 b}$-g adopts the 1,3-alt conformation. ${ }^{54}$

\section{Conclusion}

Calixarenes functionalized at their meso positions have been studied in order to achieve new products having desired properties. Since the investigation of calixarenes dealing with their

syntheses, reactivity and a large variety of applications is very intense, ${ }^{55-70}$ only selected examples of considered compounds are described in this review. 
There are relatively few reports concerning functionalization of calixarenes at meso positions, compared to reports on modification of their wide and narrow rims, therefore it seemed of interest to review works on substitution of their meso positions, and to pay attention to the usefulness of obtained species for further reactions, which are often difficult to perform using other methods.

\section{Acknowledgement}

The financial support of this work provided by Polish Science Foundation (Grant NN 209441539) is gratefully acknowledged.

\section{References}

1. Gutsche, C.D. Calixarenes: An Introduction, Monographs in Supramolecular Chemistry, Royal Soc. Chem.: Cambridge, 2008.

2. Mokhtari, B.; Pourabdollah, K.; Dalali, N. Chromatographia 2011, 73, 829.

3. Joseph, R.; Rao, C. P. Chem. Rev. 2011, 111, 4658.

4. Vicens, J.; Harrowfield, J., Eds.; Calixarenes in the Nanoworld, Springer Verlag: Dordrecht, 2007.

5. Maity, D.; Chakraborty, A.; Gunupuru, R.; Paul, P. Inorg. Chim. Acta 2011, 372, 126.

6. Matvieiev, Y.; Karpenko, I.; Kulinich, A.; Ryabitskii, A.; Pivovarenko, V.; Shishkina, S.; Shishkin, O.; Kalchenko, V. Tetrahedron Lett. 2011, 52, 3922.

7. Makrlik, E.; Vanura, P.; Selucky, P. J. Radioanal. Nucl. Chem. 2011, 287, 899.

8. Qazi, M. A.; Qureshi, I.; Memon, S. J. Fluoresc. 2011, 21, 1231.

9. Yang, Y.; Lee, E. K.; Zhou, H.; Surowiec, K.; Bartsch, R. A. J. Incl. Phenom. Macrocycl. Chem. 2011, 70, 197.

10. Hu, K.; Zhao, W.; Wen, F.; Liu, J.; Zhao, X.; Xu, Z.; Niu, B.; Ye, B.; Wu, Y.; Zhang, S. Talanta 2011, 85, 317.

11. Goodworth, K.; Hervé, A.-C.; Stavropoulos, E.; Hervé, G.; Casades, I.; Hill, A. M., Weingarten, G. G.; Tascon, R. E.; Colston, M. J.; Hailes, H. C. Tetrahedron 2011, 67, 373.

12. Solovyov, A. V.; Cherenok, S. O.; Kalchenko, O. I.; Atamas, L. I.; Kazantseva, Z. I.; Koshets, I. A.; Tsymbal, I. F.; Kalchenko, V. I. J. Mol. Liquids 2011, 159, 117.

13. Düker, M. H.; Gómez, R.; Vande Velde, C. M. L.; Azov, V. A. Tetrahedron Lett. 2011, 52 , 2881.

14. Hudecek, O.; Curinova, P.; Budka, J.; Lhoták, Tetrahedron 2011, 67, 5213.

15. Maji, P. Inorg. Chim. Acta, 2011, 372, 120.

16. Makrlik, E.; Ćajan, M.; Budka, J.; Vañura, P. Monatsh. Chem. 2011, 142, 5.

17. Sayin, S.; Yilmaz, M. Desalination 2011, 276, 328. 
18. Sliwa, W.; Kozlowski, C. Calixarenes and Resorcinarenes. Synthesis, Properties and Applications, Wiley-VCH, Weinheim, 2009.

19. Sliwa, W.; Deska, M. Arkivoc 2011, 1, 496.

20. Deska, M.; Sliwa, W. Covalently and noncovalently bound assemblies of calixarenes, Nova Science Publishers, Inc.: New York, 2011.

21. Sliwa, W.; Girek, T. J. Incl. Phenom. Macrocycl. Chem. 2010, 66, 15.

22. Sliwa, W.; Deska, M. Arkivoc 2008, 1, 87.

23. Scully, P. A.; Hamilton, T. M.; Bennett, J. L. Org. Lett. 2001, 3, 2741.

24. Hertel, M. P.; Behrle, A. C.; Williams, S. A.; Schmidt, J. A. R.; Fantini, J. L. Tetrahedron 2009, 65, 8657.

25. Gruner, M.; Fischer, C.; Gruber, T.; Weber, E. Supramolecular Chem. 2010, 22, 256.

26. Fischer, C.; Seichter, W.; Weber, E. Struct. Chem. Commun. 2010, 1, 43.

27. Fischer, C.; Gruber, T.; Seichter, W.; Weber, E. Org. Biomol. Chem. 2011, 9, 4347.

28. Gruber, T.; Gruner, M.; Fischer, C.; Seichter, W.; Bombicz, P.; Weber, E. New. J. Chem. 2010, 34, 250.

29. Atwood, J.L.; Steed, J.W. Eds, Organic Nanostructures, Wiley-VCH: Weinheim, 2008.

30. Ozcan, F.; Sahin, O.; Yilmaz, M. J. Inclusion Phenom. Macrocycl. Chem. 2009, 63, 123.

31. Itzhak, N.; Biali, S. E. J. Org. Chem. 2010, 75, 3437.

32. Simaan, S.; Biali, S. E. J. Org. Chem. 2003, 68, 3634.

33. Simaan, S.; Agbaria, K.; Biali, S. E. J. Org. Chem. 2002, 67, 6136.

34. Simaan, S.; Biali, S. E. J. Org. Chem. 2004, 69, 95.

35. Agbaria, K.; Aleksiuk, O.; Biali, S. E.; Böhmer, V.; Frings, M.; Thondorf, I. J. Org. Chem. 2001, 66, 2891.

36. Fischer, C.; Lin, G.; Seichter, W.; Weber, E. Tetrahedron 2011, 67, 5656.

37. Middel, O.; Greff, Z.; Taylor, N. J.; Verboom, W.; Reinhoudt, D. N.; Snieckus, V. J. Org. Chem. 2000, 65, 667.

38. 38 Simaan, S.; Biali, S. E. J. Org. Chem. 2003, 68, 7685.

39. Simaan, S.; Biali, S. E. Org. Lett. 2005, 7, 1817.

40. Columbus, I.; Biali, S. E. J. Org. Chem. 2008, 73, 2598.

41. Kogan, K.; Biali, S. E. J.Org. Chem. 2009, 74, 7172.

42. Kogan, K.; Columbus, I.; Biali, S. E. J. Org. Chem. 2008, 73, 7327.

43. Columbus, I.; Biali, S. E. Org. Lett. 2007, 9, 2927.

44. Kuno, L.; Seri, N.; Biali, S. E. Org. Lett. 2007, 9, 1577.

45. Kuno, L.; Biali, S. E. J. Org. Chem. 2009, 74, 48.

46. Gopalsamuthiram, V.; Predeus, A. V.; Huang, R. H.; Wulff, W. D. J. Am. Chem. Soc. 2009, $131,18018$.

47. Waters, M. L.; Wulff, W. D. Org. React. 2008, 70, 121.

48. Gopalsamuthiram, V.; Wulff, W. D. J. Am. Chem. Soc. 2004, 126, 13936.

49. Wang, H.; Huang, J.; Wulff, W. D.; Rheingold, A. L. J. Am. Chem. Soc. 2003, 125, 8980.

50. Moore, D.; Pu, L. Org. Lett. 2002, 4, 1855. 
51. Seri, N.; Thondorf, I.; Biali, S. E. J. Org. Chem. 2004, 69, 4774.

52. Kogan, K.; Biali, S. E. Org. Lett. 2007, 9, 2393.

53. Kuno, L.; Biali, S. E. Org. Lett. 2009, 11, 3662.

54. Seri, N.; Biali, S. E. J. Org. Chem. 2005, 70, 5278.

55. Genorio, B.; Subbaraman, R.; Strmcnik, D.; Tripkovic, D.; Stamenkovic, V. R.; Markovic, N. M. Angew. Chem. Int. Ed. 2011, 50, 5468.

56. Kulesza, J.; Bocheńska, M. Eur. J. Inorg. Chem. 2011, 777.

57. Mačková, M.; Himl, M.; Minářová, L.; Lang, J.; Lhoták, P. Tetrahedron Lett. 2011, 52, 2543

58. Chen, M.; Shang, T.; Liu, J.; Diao, G. J. Chem. Thermodynamics 2011, 43, 88.

59. Maffei, F.; Betti, P.; Genovese D.; Montalti, M.; Prodi, L.; De Zorzi, R.; Geremia, S.; Dalcanale, E. Angew. Chem. Int. Ed. 2011, 50, 4654.

60. Ho, I.-T.; Chu, J.-H.; Chung, W.-S. Eur. J. Org. Chem. 2011, 1472.

61. Solangi, I. B.; Bhatti, A. A.; Kamboh, M. A.; Memon, S.; Bhanger, M. I. Desalination 2011, 272, 98.

62. Bonvallet, P. A.; Mullen, M. R.; Evans, P. J.; Stoltz, K. L.; Story, E. N. Tetrahedron Lett. 2011, 52, 1117.

63. Fang, L.; Wang, C.; Fahrenbach, A. C.; Trabolsi, A.; Botros, Y. Y.; Stoddart, J. F. Angew. Chem. Int. Ed. 2011, 50, 1805.

64. Memon, S.; Memon, N.; Memon, S.; Latif, Y. J. Hazardous Materials 2011, 186, 1696.

65. da Silva, D. L.; do Couto Tavares, E.; de Souza Conegero, L.; de Fatima, A.; Pilli, R. A.; Fernandes, S. A. J. Incl. Phenom. Macrocycl. Chem. 2011, 69, 149.

66. Chennakesavulu, K.; Raviathul Basariya, M.; Sreedevi, P.; Bhaskar Raju, G.; Prabhakar, S.; Rao, S.S. Termochimica Acta 2011, 515, 24.

67. Kim, S.-H.; Hwang, I.-J.; Gwon, S.-Y.; Burkinshaw, S. M.; Son, Y.-A. Dyes and Pigments 2011, 88, 84.

68. Morales, A.; Santana, A.; Althoff, G.; Melendez, E. J. Organomet. Chem. 2011, 696, 2519.

69. Monnereau, C.; Rebilly, J.-N.; Reinaud, O. Eur. J. Org. Chem. 2011, 166.

70. Gharib, F.; Hajmalek, M.; Alamoti, R. A.; Farajtabar, A. J. Mol. Liquids 2011, 159, 161. 